\title{
From particles to patients: oxidative stress and the cardiovascular effects of air pollution
}

\section{Mark R Miller*1, Catherine A Shaw' \& Jeremy P Langrish'}

'BHF/University Centre for Cardiovascular Science, University of Edinburgh, Queens Medical Research Institute, 47 Little France Crescent, Edinburgh, EH16 4TJ, Scotland, UK

*Author for correspondence: Tel. : +44 1312429334 m Fax: +44 1312429215 m mark.miller@ed.ac.uk

Air pollution, especially airborne particulate matter (PM), is associated with an increase in both morbidity and mortality from cardiovascular disease, although the underlying mechanisms remain incompletely established. The one consistent observation that links the pulmonary and cardiovascular effects of inhaled PM is oxidative stress. This article examines the evidence for the role of oxidative stress in the cardiovascular effects of air pollution, beginning with observations from epidemiological and controlled exposure studies and then exploring potential mechanistic pathways involving free radical generation from PM itself, to effects of PM on cell cultures, isolated organs, healthy animals and animal models of disease. Particular emphasis is placed on the vascular and atherosclerotic effects of urban air pollution and diesel exhaust emissions as rich sources of environmental ultrafine particles.

The WHO recently issued a statement estimating that over 1 million deaths worldwide can be attributed to the effects of air pollution, (over and above that accounted for by conventional risk factors; see $[1,301])$. The magnitude of these effects may be staggering; however, air pollution has long been recognized as being detrimental to health. Episodes of air pollution, such as the 'great smog of London' in 1952 [302], result in large numbers of deaths from cardiorespiratory diseases, leading the scientific community, politicians and the general public to consider the need to improve air quality. Until two decades ago, however, attention largely focused on the respiratory effects of air pollution, where there is a clear link between episodes of high air pollution and a worsening of allergic and inflammatory conditions of the lung, such as asthma and chronic obstructive pulmonary disease. More recent evidence demonstrates clear associations between air pollution and cardiovascular disease, and due to the high prevalence of cardiovascular disease in the western world, the cardiovascular effects of air pollution are arguably greater than those attributed to pulmonary consequences.

There is now a wealth of evidence linking exposure to urban air pollution, especially airborne particulate matter (PM), to adverse effects on the cardiovascular system, yet the mechanisms underlying these effects remain incompletely explained. Local and systemic oxidative stress has emerged as the likely common link between pulmonary exposure and systemic effects, including the cardiovascular system [1]. This article has been structured to introduce the subject of the cardiovascular effects of air pollution through an overview of the epidemiological studies, followed by a summary of controlled exposure studies, which highlight the wide-ranging effects of air pollution. The article describe the evidence for the role of oxidative stress in the cardiovascular effects of air pollution, beginning with clinical observations and then taking a step-wise approach to explore potential mechanistic pathways involving free-radical generation from PM itself, to effects of PM on cell cultures, isolated organs, healthy animals and models of disease. The article focuses on the action of (outdoor) urban air pollution and vehicle exhaust emissions, placing particular emphasis on the vascular and atherosclerotic effects of the particulate components of these common pollutants.

\section{What is air pollution?}

Air pollution is a complex mixture of gaseous, volatile, semi-volatile and PM (Figure 1A). The composition of the air pollution varies greatly, depending on the source of the pollutant, environmental factors, such as the meteorological conditions, time and day of the week, industrial activity and traffic density. While gaseous air pollutants, such as ozone, nitrogen

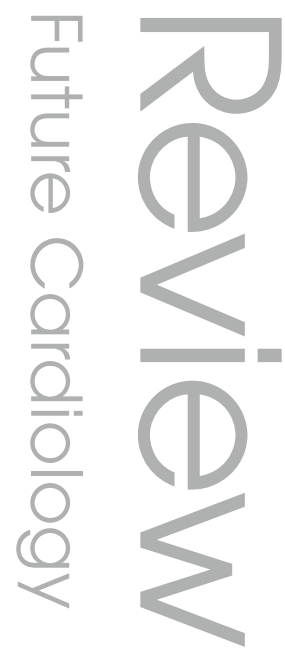

\section{Keywords}

- air pollution $=$ atherosclerosis - cardiovascular $n$ diesel exhaust $=$ endothelium $=$ free radical $=$ nitric oxide - oxidative stress = particulate matter $=$ superoxide

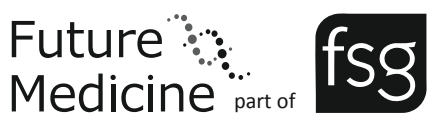




\section{Review Miller, Shaw \& Langrish}

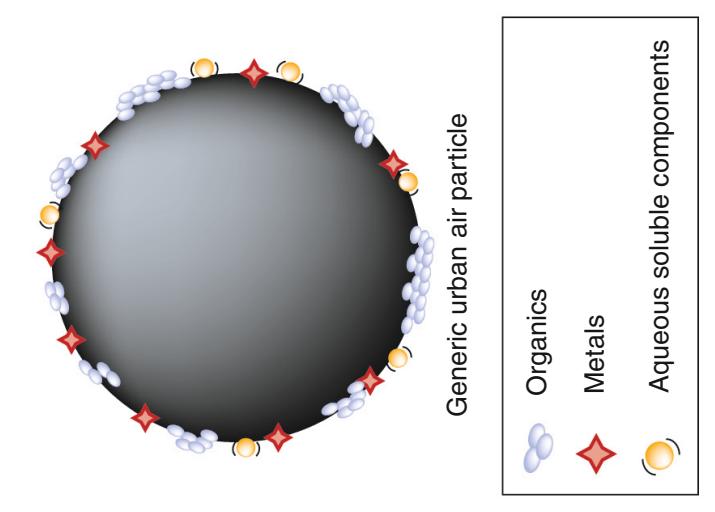

()
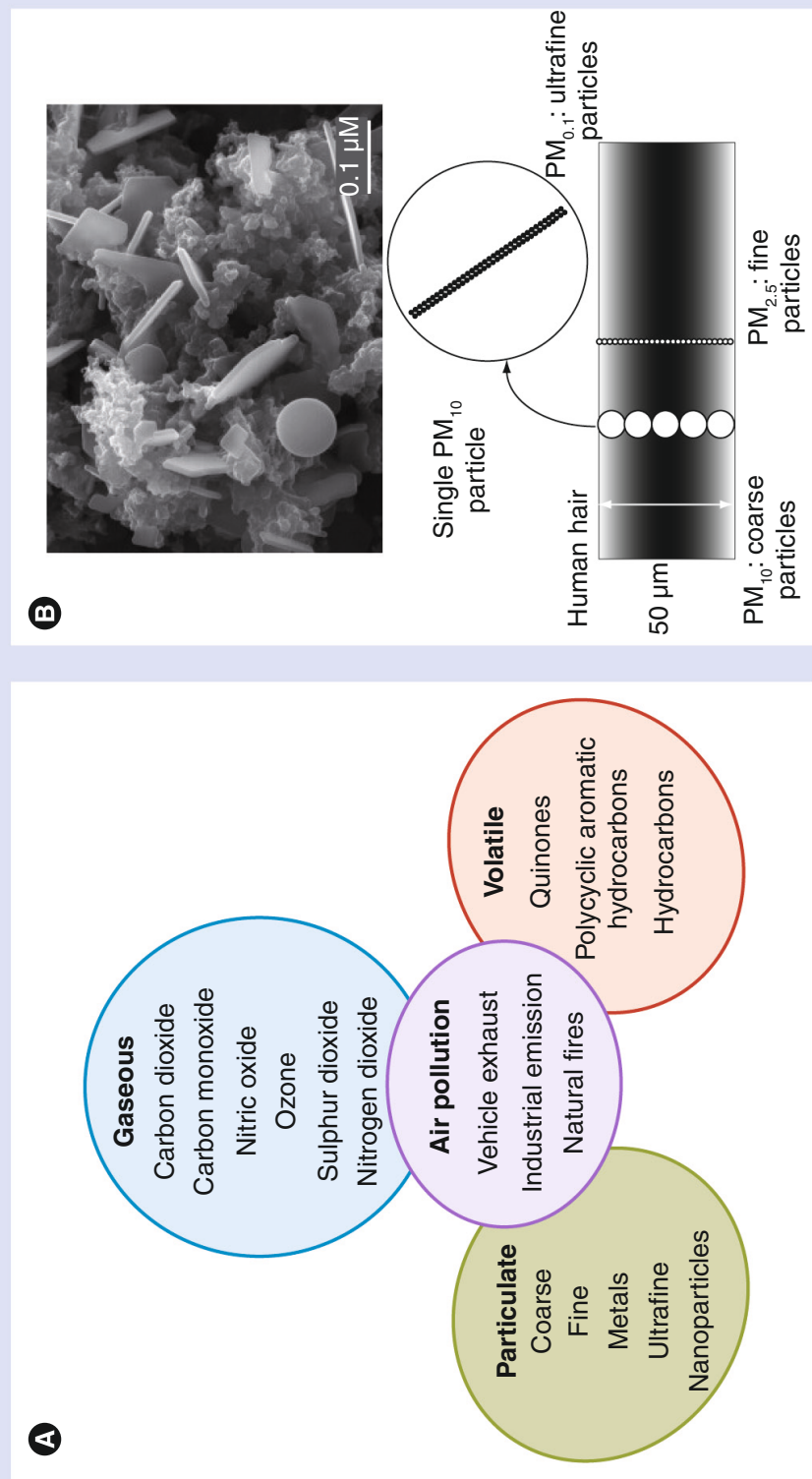
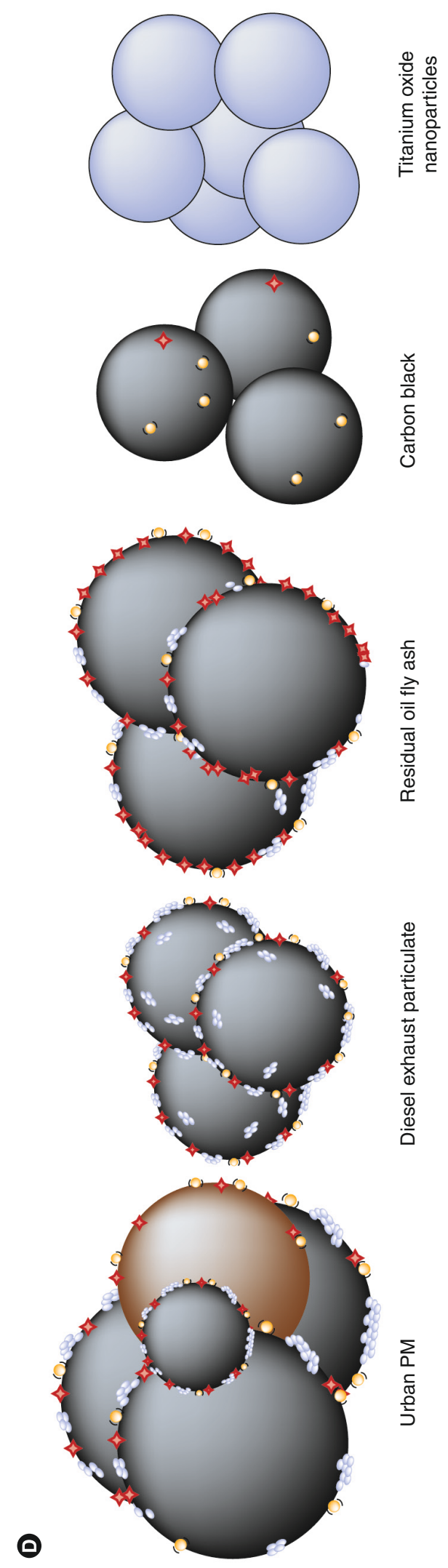
Figure 1. Composition and categorization of air pollution (see figure on page 578). (A) Separation of air pollution into the overlapping fractions of gases, volatile liquid droplets and particulate components. (B) Categorization of different size ranges of PM. Inset shows a scanning electron micrograph of PM collected from the city center of Louisville, KY, USA in 2007, highlighting the wide range of particle sizes, shapes and surface characteristics of urban PM. (C) The main groups of constituents of an urban air particle. Reactive transition metals and many organic chemicals (e.g., quinones and polyaromatic hydrocarbons) have the potential to generate reactive oxygen species, alone and especially through reaction with each other or cellular components. (D) Differences in composition of different types of environmental and model PM. Urban PM represents a mixed and very variable set of particles. A large proportion of the mass will be large particles (with micrometer diameter); however, a sizable proportion of the number of the particles are often in the nanometer range $(<100 \mathrm{~nm}$ diameter). Diesel exhaust particulate (DEP) are aggregates of particles with a primary particle size of between 20-100 nm. The composition will vary considerably depending on the source of DEP, however, often they are rich in metal and organic constituents. Residual oil fly ash particles are relatively large particles (generally a low micromolar diameter), often used in experimental studies as a metal-rich source of PM. Carbon black is a 'pure' model carbon particle, often used as a 'clean' source of carbon or negative control particle. It can be produced in specific size ranges; however, most frequently ultrafine carbon particles are used (e.g., as a comparator to DEP with a similar surface area of carbon). Carbon black does have the capacity to generate superoxide free radicals and has biological actions, therefore, titanium dioxide $\left(\mathrm{TiO}_{2}\right)$ can also used be as a negative control particle. Many types of $\mathrm{TiO}_{2}$ are inert unless extremely high concentrations are used. Thus, ultrafine $\mathrm{TiO}_{2}$ acts comparator to DEP or carbon black with a similar, but unreactive, surface area.

PM: Particulate matter; ROS: Reactive oxygen species.

(B) Reproduced with permission from [121].

oxides and carbon monoxide can undoubtedly have serious health effects, epidemiological evidence suggests that the strongest associations are linked to the PM of air pollution. PM is further divided into coarse, fine and ultrafine fractions (Figure 1B). Large 'coarse', particles (termed $\mathrm{PM}_{10}$; particles with a diameter less than $10 \mu \mathrm{m}$ ) form much of the overall mass of PM and can be derived from numerous sources, such as silicabased crustal particles (e.g., soil, sand and volcanic ash), burning of natural materials (e.g., woodsmoke) or wear of machinery (e.g., vehicle braking and tyre erosion). 'Fine' $\left(\mathrm{PM}_{2.5}\right.$ : particles with a diameter less than $2.5 \mu \mathrm{m})$ and 'ultrafine' $\left(\mathrm{PM}_{0.1}\right.$ : particles with a diameter less than $100 \mathrm{~nm}$ ) PM are generally derived from industrial burning of fossil fuels and from traffic-related sources. It is these fractions that are believed to be especially important as they are inhaled deep into the airways [2]. Due to the difficulties in measuring environmental PM, epidemiological studies are currently limited to studying either $\mathrm{PM}_{10}$ or $\mathrm{PM}_{2.5}$, although it is worth noting that $\mathrm{PM}_{10}$ will include coarse, fine and ultrafine particles (UFPs) together, and $\mathrm{PM}_{2.5}$ will encompass both fine and UFPs. However, the availability of precollected PM allows preclinical studies to use exposures of specific size ranges of PM, notably UFPs, in isolation.

\section{Ultrafine particles}

In recent years, increasing concerns have been leveled at the ultrafine component of PM (UFPs or nanoparticles). UFPs and nanomaterials are now engineered for a staggering variety of uses $[3,303]$; however, the potential for high levels of exposure tend to be restricted to the site of manufacture itself. However, combustionderived nanoparticles from vehicle exhausts represent a clear hazard to the widespread population. Diesel exhaust is an important component of urban outdoor air pollution, often comprising approximately $20 \%$ (range: 6-41\%) of the mass of the airborne PM [4]. Diesel vehicles are often considered to be more environmentally friendly as the exhaust contains lower levels carbon dioxide emissions - contributing to the increased popularity for this type of vehicle - however, PM emissions are around 100-fold higher than gasoline engines [5-7]. Particles from the burning of fuel are carbon based, but contain a host of potentially toxic and carcinogenic organic chemicals and reactive metals on their surface (Figure 1C \& D). Therefore, ultrafine diesel exhaust particulate (DEP) have an extremely large surface area for a given mass, engendering them with the capacity of to carry large amounts of reactive chemicals into the body.

\section{Air pollution exposure \& cardiovascular epidemiology}

A number of large epidemiological studies have repeatedly demonstrated the association between exposure to air pollution and increased morbidity and mortality (see $[1,8-10]$ for recent reviews). In a landmark paper, Dockery and colleagues reported a prospective cohort study of 8111 adults residing across six major cities in the USA. They demonstrated that after adjustment for baseline differences, the rate ratio of mortality between the least polluted city and the most polluted city was 1.26 [11]. These associations were found for combustion-derived fine PM, but not crustal fine PM or coarse PM [12].

These findings were strengthened by a prospective cohort study of 1.2 million adults across the 50 US states, which demonstrated strong associations between air pollution and 
all-cause cardiorespiratory and lung cancer mortality [13]. Although the magnitude of these associations varies between studies it is now accepted that the increase in mortality is a robust and reproducible finding [1].

The relationship between air pollution exposure and morbidity/mortality are strongest for cardiovascular diseases such as myocardial infarction. A number of meta-analyses and multicity studies of daily changes in exposure to PM have demonstrated an increase of approximately $0.5-2 \%$ in cardiovascular mortality with each $10-20 \mu \mathrm{g} / \mathrm{m}^{3}$ increase in particulate air pollution [14-20]. Furthermore, acute exposure to traffic-derived PM has been linked to the triggering of acute myocardial infarction, suggesting a direct causal link $[21,22]$. In a recent metaregression analysis, Nawrot and colleagues assessed the triggers of acute myocardial infarction and found that traffic exposure was in fact the highest population-attributable risk factor for the triggering of nonfatal myocardial infarction [23]. The magnitude of risk was similar to that of more commonly accepted triggers, such as physical exertion. Thus, there is evidence for both acute and chronic effects underlying the action of PM exposure in man.

\section{Oxidative stress}

Oxidative stress is defined as the generation of reactive oxygen species (ROS) over and above that which the body's defences can remove. Oxygen-derived free radicals such as superoxide $\left(\mathrm{O}^{2-}\right)$ and hydroxyl free radicals, as well as other oxidants, such as hydrogen peroxide and peroxynitrite, are the key mediators that drive oxidative stress and impair cellular function. Free radical generation is a normal by-product of cellular respiration and redox regulation of proteins is integral to normal cellular function. However, depletion of antioxidants can lead to build up of free radicals to an extent that contributes towards disease processes. This is especially important in the vascular system. Atherogenesis involves the formation of plaques on the inner surface of arteries, driven by the accumulation of oxidized lipids within the intimal layer and a subsequent inflammatory response $[24,25]$. Oxygen free radicals contribute to this process by activating inflammatory cells and oxidizing circulating lipids, promoting their accumulation. However, the vascular effects of oxidative stress are perpetuated by the reaction of $\mathrm{O}^{2-}$ with the endothelium-derived mediator, nitric oxide (NO), leading to generation of the detrimental mediator peroxynitrite (a nitrating and oxidising species, and weak vasoconstrictor), but more importantly limiting the many beneficial actions of NO, such as vasodilatation, inhibition of platelet activation/aggregation, regulation of inflammatory cells and suppression of smooth muscle cell proliferation/migration. Indeed vascular endothelial dysfunction (often defined by the reduced NO bioavailability) can be detected before the development of overt atherosclerosis in patients that have risk factors for cardiovascular diseases. Thus, endothelial dysfunction is recognized as one of the earliest signs of atherosclerosis and is an independent predictor of future cardiovascular events [26].

\section{Particles as a cause of oxidative stress?}

The precise mechanisms by which inhaled particles exert their adverse effects on the cardiovascular system are unclear. Very briefly, there are three leading hypotheses as to the pathways linking the pulmonary and cardiovascular effects (Figure 2; see [27] for further details): it has been proposed that particles inhaled into the lungs may trigger an inflammatory response within the alveolae, with a subsequent secondary systemic inflammatory effect resulting in cardiovascular effects [28]. Alternatively, the low nanometer size of inhaled particles may allow them to translocate across the alveolar membrane [29-32], gaining access to the bloodstream and directly influencing the vascular endothelium. Particles may trigger sensory receptors on the alveolar surface, resulting in alterations in autonomic nervous system activity leading to indirect alterations to cardiovascular function. Other pathways may also contribute, including translocation and stimulation of sensory receptors in the upper airways and nasal epithelium, translocation across the GI tract after mucociliary clearance, accumulation of particle constituents and amplification of inflammatory pathways in adipose tissue and effects on the CNS that may regulate endocrine pathways, although these are outside the scope of this review. There is good evidence for all three of the main hypotheses and each pathway may play an important role in the overall cardiovascular response. Importantly though, regardless of which pathway predominates, there is a potential role for oxidative stress at numerous points of all three pathways (Figure 2A).

Numerous types of PM have the capacity to generate oxygen free radicals (see 'Particles as a direct source of free radicals'). The oxidative capacity of particulates varies with the 

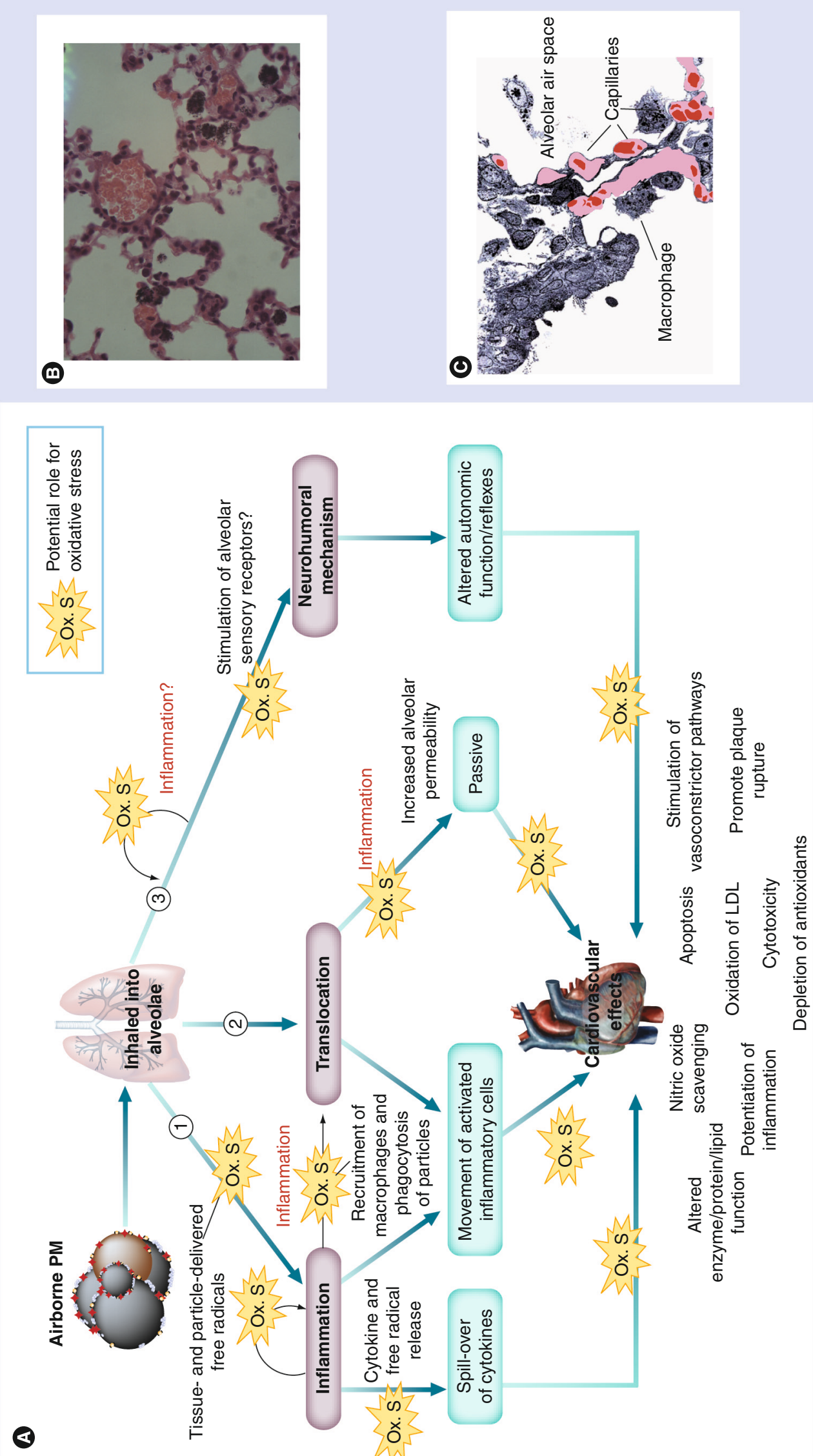
physiochemical characteristics of the particle type and the biological environment it gains access to. In vitro studies have demonstrated a clear link between the biological actions of particulates and levels of free radicals and in vivo studies consistently find evidence for increased levels of oxidative stress in PM exposed animals. At present, though, it is unclear if particlederived oxidative stress mediates the cardiovascular actions of inhaled particles. In this article a step-wise approach to the evidence for the role of oxidative stress in the cardiovascular actions of particulate air pollution is used, highlighting similarities and differences that link together data from a range of experimental approaches.

\section{Controlled exposures of air pollutants} Benefits of controlled exposure studies

The epidemiological evidence for the cardiovascular effects of air pollution are compelling; however, this type of study is subject to different forms of bias and cannot investigate biological mechanisms, especially in terms of causality. To this end controlled exposure studies are required to assess the possible underlying pathophysiological mechanisms responsible for the observed acute and chronic effects of exposure to air pollutants. One clear benefit of controlled exposures is that, unlike studies in 'real-world' environments, they are both predictable and controllable [33]. Furthermore, they can be used to separate out the differing effects of distinctive components of the air pollution mixture. In light of the epidemiological evidence, controlled exposure studies that focus on the cardiovascular system, have focused predominantly on the effects of combustionderived PM, using either concentrated ambient particles (CAPs) from urban environments or dilute diesel exhaust to generate the exposures, in comparison to a control exposure of filtered clean air.

\section{Air pollution has multiple actions on the cardiovascular system}

Controlled exposure studies in man have demonstrated important early changes in arterial hemodynamics as a result of PM exposure. Exposure to CAPs with ozone or dilute diesel exhaust leads to acute vasoconstriction of the brachial artery in both healthy volunteers and patients with metabolic syndrome [34-36], as well as an immediate and transient increase in central arterial stiffness, consistent with increases in arterial tone [37]. Accordingly, shortly after exposure to CAPs and ozone there is a small increase in diastolic and mean arterial blood pressure [35,38]. These acute effects may be driven by autonomic reflexes and changes in sympathetic nervous system activity [1]. Heart rate variability (HRV) has been used to explore the action of inhaled PM on these pathways. Although data from controlled exposure studies are limited and somewhat inconsistent, PM exposure is generally associated with a reduction in HRV, suggesting that autonomic activity is altered by the exposure itself [1]. The reduction in HRV following exposure to CAPs [39-42] but not following dilute diesel exhaust exposure [43], suggests that the composition of the PM is critical for these actions.

Continuous electrocardiography during exposure to dilute diesel exhaust revealed an exacerbation of exercise-related myocardial ischemia in men with coronary heart disease [44]. These findings concur with those from observational panel studies showing an association between the risk of ECG ST-segment depression and increasing exposure to ambient PM [45-49].

Controlled exposures to dilute diesel exhaust or CAPs with ozone are associated with impaired vascular vasomotor function due to endothelial dysfunction. These effects do not appear to be present immediately following the exposure but can be demonstrated from as early as $2 \mathrm{~h}$ after the exposure and up to $24 \mathrm{~h}$ [50-52], and have been shown to be mediated by the particulate phase of the inhaled pollutants [53].

Acute clinical cardiovascular events are primarily driven by arterial thrombosis complicating atheromatous plaque rupture. As well as the alterations in hemodynamics and vascular endothelial function that may predispose to plaque instability and rupture, exposure to PM has been shown to increase thrombus formation at sites of arterial injury [54]. This increase in thrombogenicity is associated with an increase in platelet activation, suggesting this as a likely mechanism. Thrombus formation is highly dynamic and generation is balanced by clot turnover and breakdown (e.g., by release of the endogenous fibrinolytic enzyme tissue plasminogen activator from the vascular endothelium). The ability of the endothelium to release tissue plasminogen activator is also impaired following exposure to dilute diesel exhaust [51].

Long-term exposure to PM also promotes the development of atheromatous plaques. Much of this evidence is derived from animal models of atherosclerosis (see PM and oxidative stress in animal models of atherosclerosis), although observational studies in man have demonstrated that those living close to a major road 
have increased coronary artery calcium scores (a marker of complex atherosclerotic plaques), after correction for potential confounders [55]. Additionally, background residential exposure to $\mathrm{PM}$ is associated with an increase in carotid intima-medial thickness (another surrogate marker of atheroma burden) [56,57] and accelerated atheroma progression, albeit in a highly selected population [58].
The adverse cardiovascular effects of exposure to PM air pollution are summarized in Figures $3 \& 4$. Whilst these observations may help to explain the documented increase in cardiovascular events in those exposed to high levels of PM, the fundamental mechanism linking them remains elusive. Currently, oxidative stress is unique in that it has the potential to drive all of the above actions of PM, both locally and on a systemic level [1].

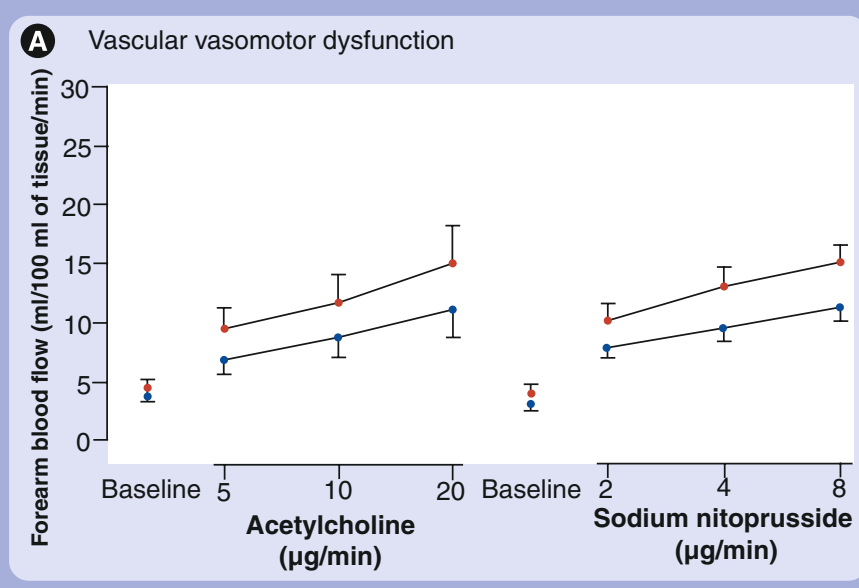

B Increased thrombotic tendency

(

Impairment of fibrinolytic function
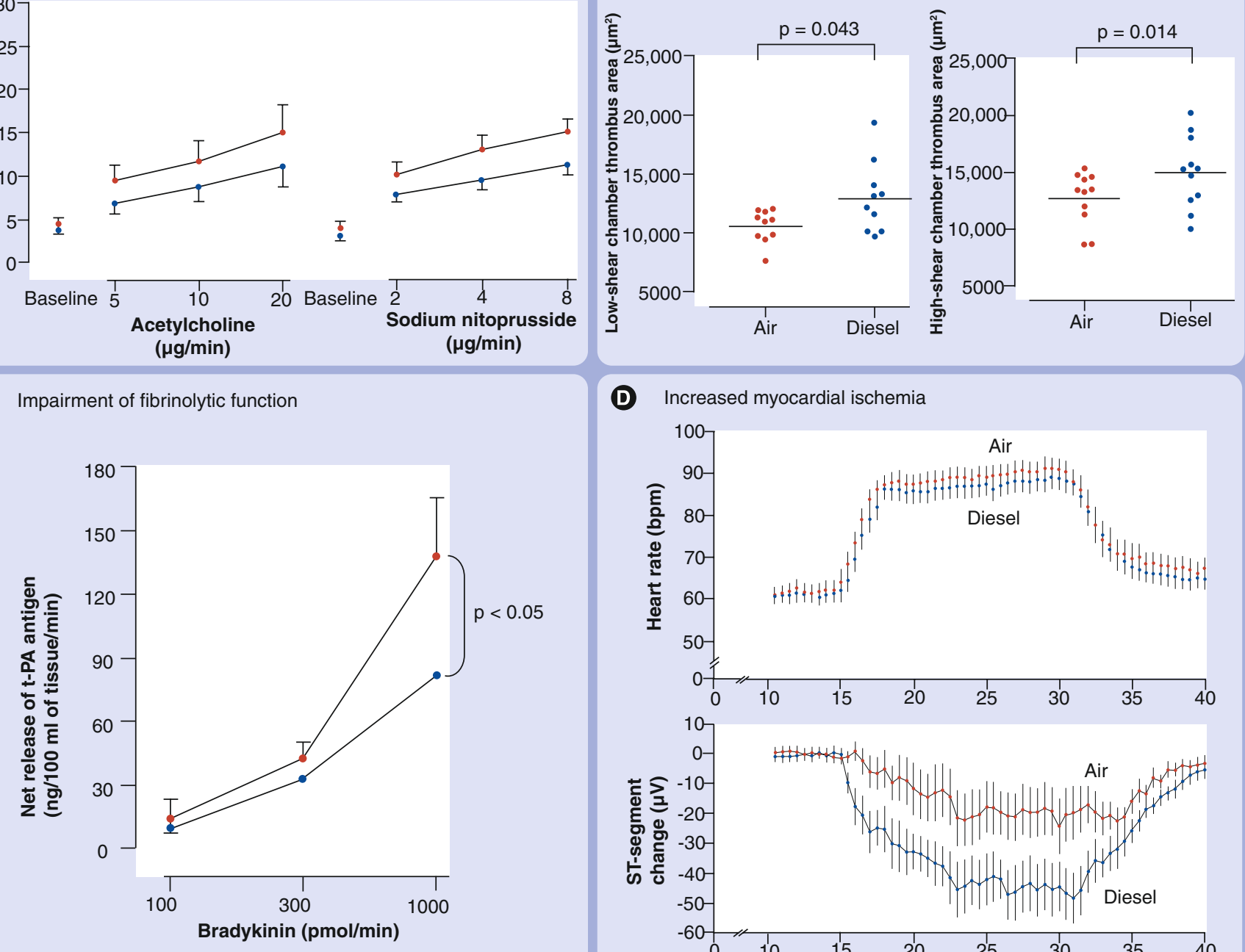

D Increased myocardial ischemia
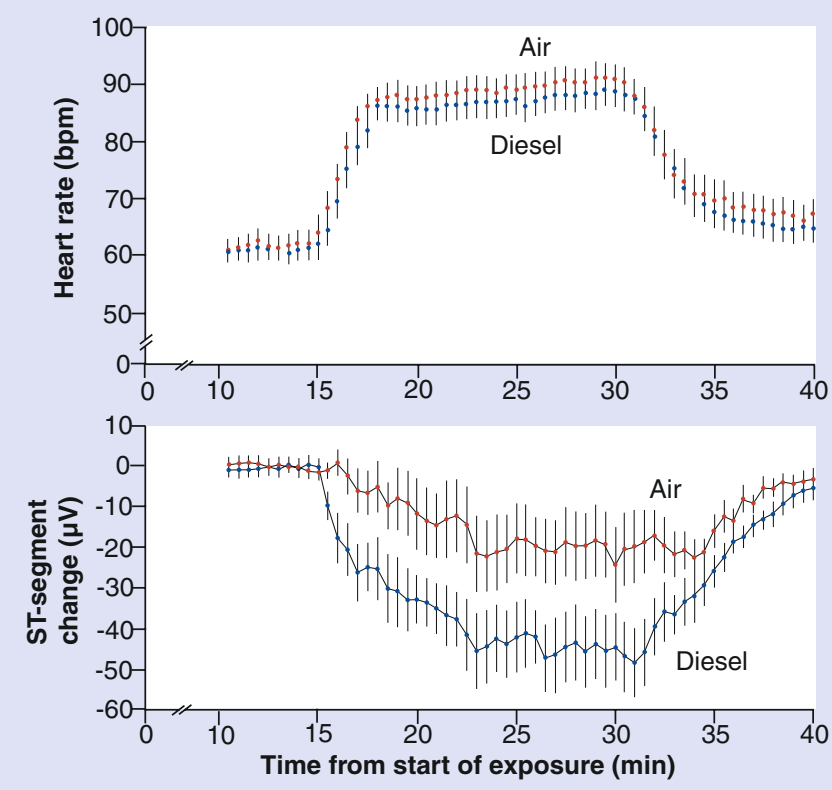

Figure 3. Four examples of cardiovascular impairment following exposure to diesel exhaust in man. (A) Impairment of vasodilatation (measured as increased forearm blood flow) to endothelium-dependent (acetylcholine) and -independent (sodium nitroprusside) nitric oxide-mediated vasodilators. (B) Increased blood thrombogenicity (measured as ex vivo thrombus formation on the surface of a denuded arterial strip within a Badimon chamber). The low shear chamber mimics flow conditions of a mild-to-moderately stenosed coronary artery, high shear chamber mimics a patent coronary artery. (C) Impaired fibrinolysis (measured as release of t-PA in response to bradykinin infusion). (D) Increased myocardial ischemia (measured as increased ST-segment depression, using a 12-lead ECG during a 15 min exercise test). Volunteers were exposed to filtered air (red circles) or diluted diesel exhaust (300-350 $\mu \mathrm{g} / \mathrm{ml}^{3}$; blue circles) for 1 or $2 \mathrm{~h}$.

bpm: Beats per min; t-PA: Tissue plasminogen activator.

(A \& C) Data taken from [51].

(B) Data taken from [54].

(D) Data taken from [44]. 


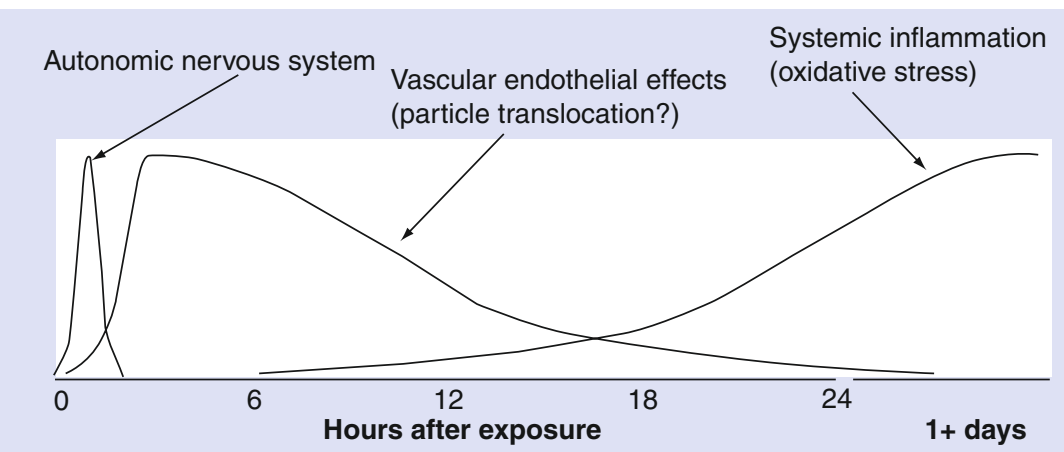

Arterial vasoconstriction/increased arterial tone

Reduced heart rate variability

Increased blood pressure

Increased myocardial ischemia

Impaired vascular vasomotor function

Reduced endogenous fibrinolysis

Increased thrombogenicity

Platelet activation

Local and systemic inflammation/oxidative stress

Accelerated atherogenesis and progression

Figure 4. The time course and numerous ways inhaled particulate matter alters cardiovascular function. These diagrams are based largely on controlled exposures of concentrated ambient particles and dilute diesel exhaust in Edinburgh, Scotland, as well as inhalation of urban particulate matter in Bejing, China city center [43,44,51,52,54,201,202]. from man, other than blood and urine, there is subsequently a paucity of direct evidence for the role of oxidative stress following air pollution exposure in humans.

\section{Epidemiology \& clinical evidence}

Panel \& cross-sectional studies

Among 60 subjects with coronary heart disease living in a retirement community in Los Angeles (CA, USA), airborne PM air pollution was associated with an increase in airway [62] and systemic inflammation [63]. These airway and systemic inflammatory responses correlated strongly with the ability of the PM to produce reactive oxygen free radicals in an in vitro rat macrophage assay. More convincingly, a study of 76 students living in Taipei (Taiwan) found that increasing background levels of PM were associated with a reduction in HRV, accompanied by an increase in plasma levels of 8-hydroxy-2'-deoxyguanosine (8-OH-dG) [64], an oxidative modification of a DNA adduct that is considered to be a stable and reliable biomarker of oxidative stress [65]. Similar increases in urinary $8-\mathrm{OH}-\mathrm{dG}$ were found with increasing levels of background air pollution in men attending for follow-up in the Normative Aging Study in Boston, (MA, USA) [66] and among bus drivers and garage-men (careers that have high occupational exposure to combustionderived PM) and policemen working within the city of Prague (Czech Republic) [67,68]. Similarly, urinary malondialdehyde (a relatively nonspecific marker of oxidation) was associated with the daily PM levels (and especially the metal content within the PM), on the same day to 2 days prior to measurement, in 120 school children across four cities in China and Korea [69].

Blood has also been assessed for markers of oxidation in haemoglobin ( $\gamma$-glutamylsemialdehyde, 2-aminoadipic semialdehyde), plasma proteins (plasma protein 2-aminoadipic semialdehyde: 'PLAAS') and plasma lipids (malondialdehyde). These markers were assessed in students living and working in central Copenhagen (Denmark), in a repeated measures study design and were found to correlate well with personal measurements of PM exposure [70]. Exposure to black carbon (a surrogate measure of predominantly carbon-centered combustion-derived PM) was associated with an increase in plasma PLAAS. Other variables were unchanged, although plasma malondialdehyde increased with $\mathrm{PM}_{2.5}$ exposure in women, but not in men, suggesting that sex differences and some degree of compartmentalization may add to the complexity of systemic PM responses. A study in an elderly group of 
28 nonsmokers found associations with outdoor black carbon/PM 2.5 and blood pressure, a reduction in brachial artery diameter and raised levels of the oxidative marker plasma thiobarbituric acid reactive substances [71]. Another study noted a very small increase in blood pressure associated with raised levels of black carbon in elderly men, but there was no evidence of interaction with gene variants linked to antioxidant defence [72]. Finally, several constituents from different sources of air pollution were found to be associated with an increase in systemic inflammation in patients with coronary artery disease, but had variable effects on levels of different erythrocyte antioxidant enzymes [73].

\section{Controlled exposure studies}

Exposure to dilute diesel exhaust results in localized airway inflammation, recruitment of neutrophils and lymphocytes into the airways and release of cytokines. In parallel to this inflammatory effect, there is an increased flux of glutathione and ascorbate (two key components of antioxidant defence) into the lung lining fluid, presumably as a compensatory mechanism to PM-induced oxidative insult [74,75]. Similarly, a $2 \mathrm{~h}$ exposure to CAPs results in an increase in total 8-isoprostane (the gold standard clinical assay of oxidative stress) concentrations in exhaled breath condensate, an effect that was still evident $24 \mathrm{~h}$ after exposure [76].

Controlled exposures clearly demonstrate oxidative stress within the lungs and attention is beginning to focus on the cardiovascular actions of these exposures. Vascular vasomotor function, assessed using venous occlusion plethysmography with infusion of intra-arterial vasodilators, is impaired following exposure to dilute diesel exhaust as compared with filtered air. Both the vasodilatation in response to infusion of the endothelium-dependent $\mathrm{NO}$-mediated vasodilators (e.g., acetylcholine (ACh) and bradykinin) and endothelium-independent $\mathrm{NO}$-mediated vasodilators (e.g., NO donor drugs such as sodium nitroprusside [SNP]) are attenuated, whilst NO-independent vasodilatation (e.g., an opener of L-type calcium channels on vascular smooth muscle cells, such as verapamil) is unaffected (Figure 5A) [51]. Whilst this is indirect evidence for a role of oxidative stress, these results are consistent with the reduced NO bioavailability due to scavenging of $\mathrm{NO}$ by $\mathrm{O}^{2-}$ free radicals (FIGURE 6) [51].

Giving plausibility to an increase in oxidative stress following PM exposure in man, Kaufman and colleagues assessed differential gene expression in peripheral blood monocytes from 11 subjects exposed to dilute diesel exhaust or filtered air. A number of genes related to oxidative stress pathways were differentially regulated between diesel exhaust and air exposed volunteers [77]. In particular there was an upregulation of HO-1 and peroxiredoxin, key enzymes involved in the reduction of oxidized molecules, and a downregulation of glutamate-cysteine ligase, an enzyme which provides the rate-limiting step in the production of the antioxidant glutathione, and the oxidant stress response molecules serine/threonine kinase 25 and activating transcription factor 6 [77].

Other studies have failed to demonstrate evidence of increased oxidative stress following exposure to certain sources of CAPs. Efficient filtration of indoor air using High-Efficiency Particulate Arresting (HEPA) filters was carried out in Copenhagen, Denmark [78] and Smithers, Canada (an area known to be heavily impacted by residential wood smoke) [79]. While there was a marked reduction in indoor particle concentrations and an associated improvement in microvascular function (measured using a reactive hyperemia reactive hyperemia peripheral arterial tonometry technique), there were no changes in markers of systemic oxidative stress (8-isoprostanes, PLAAS or malonaldehyde) [78,79]. In addition, a 2-h exposure to diesel exhaust was not associated with significant changes in urinary isoprostane F2 $\alpha$, urinary $8-\mathrm{OH}-\mathrm{dG}$ or plasma ascorbic acid (3 or $22 \mathrm{~h}$ after exposure), in comparison with levels after a similar period of filtered air exposure, in ten patients with metabolic syndrome without cardiovascular disease [80].

Interestingly, there is some evidence that the endogenous activity of the antioxidant defence mechanisms varies greatly between individuals, and therefore, could explain some of the inconsistencies in the oxidative actions of PM between studies. A randomized double-blind study exposed 19 volunteers, with a documented allergy to ragweed allergen, to the allergen with or without DEP. The phenotypes of the subjects' glutathione- $S$-transferase (GST) isoforms (a family of enzymes that mediates detoxification processes with the aid of antioxidant glutathione) were determined. There was an enhanced inflammatory response to the allergen if DEP were present, but only in subjects who were GST null [81]. Finally, a recent study exposure to diesel exhaust was associated with a reduction in proteasome activity in both red and white blood cells [82]. The activity of proteasomes is closely linked to adaptive mechanisms to oxidative stress, and 


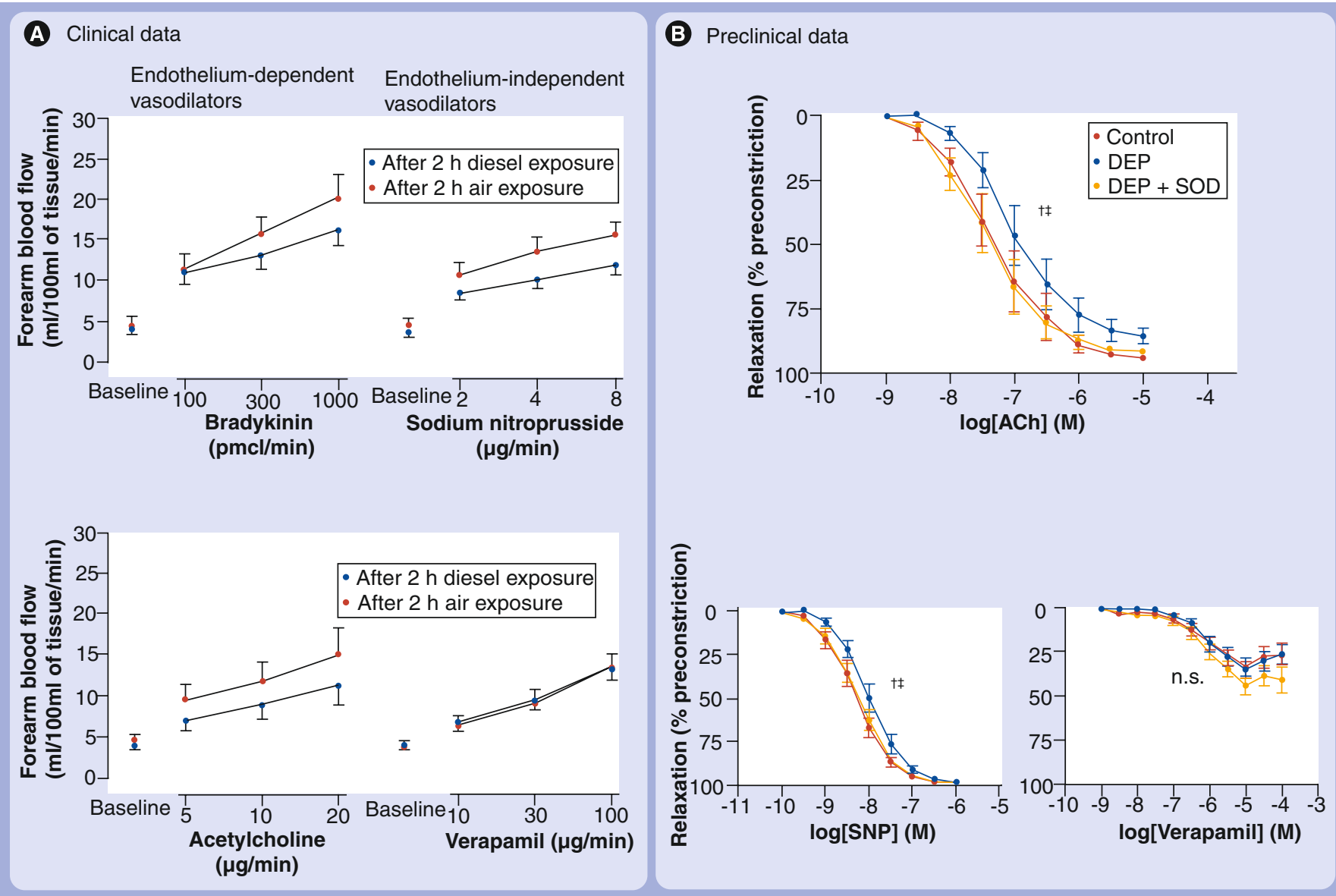

Figure 5. Inhibition of nitric oxide-mediated vasodilatation by diesel exhaust in man, and diesel exhaust particle application to rodent arteries. (A) Forearm blood flow in subjects $\sim 4 \mathrm{~h}$ after $2 \mathrm{~h}$ diesel exposure (blue circles) or air (red circles) during intrabrachial infusion of bradykinin, acetylcholine, sodium nitroprusside and verapamil. Comparing diesel exhaust exposure versus air: bradykinin $p<0.05$, acetylcholine $p<0.05$, sodium nitroprusside $p<0.001$, and verapamil $p=n$.s. (B) Direct administration of diesel exhaust particles $(10 \mu \mathrm{g} / \mathrm{ml} \mathrm{DEP}$; blue lines) to segments of isolated rat aorta in a myograph. Red lines represent no particle treatment. The effects of DEP are prevented by co-administration of (9100 U/ml; yellow lines).

Significance values shown are:

${ }^{+}$Control versus DEP'.

${ }^{\ddagger}$ DEP versus DEP + SOD'. Note the similar pattern of inhibition by the exposure between clinical and preclinical studies: impairment of endothelial-dependent nitric oxide-mediated vasodilatation (acetylcholine and bradykinin) and endothelial-independent vasodilatation (sodium nitroprusside), but not nitric oxide-independent vasodilatation (verapamil).

DEP: Diesel exhaust particle; n.s.: Not significant; SOD: Superoxide dismutase.

(A) Reproduced with permission from [51].

(B) Reproduced with permission from [88].

these pathways merit further investigation in future studies [82].

Summary evidence

A recently published meta-analysis of the studies addressing the question of oxidative stress and PM scrutinized the evidence from the controlled exposures, panel studies and cross-sectional investigations. The study emphasized the difficulties in accurately comparing such studies, particularly in relation to the differences in exposure types and concentrations, as well as the variable quality of the biomarkers and measurement errors. The authors concluded that there is a consistent and reliable relationship between exposure to combustion-derived PM and oxidative DNA adducts and lipid-peroxidation markers in urine, blood and exhaled-breath condensate [83]. Although further studies are required to determine a cause and effect relationship, this analysis clearly states the importance of oxidative stress as a central mediator of the adverse systemic effects of inhaled PM.

\section{Particles as a direct source of free radicals}

Environmental PM readily generates oxygenderived free radicals in physiological solutions. 
This has been demonstrated using a range of assays, including cytochrome $\mathrm{c}$ reduction $[84,85]$, ascorbate oxidation [86], reaction with fluorescent compounds [87] or electron paramagnetic resonance $[88,89]$. These observations are strengthened by the use of free radical scavengers or antioxidant enzymes, such as superoxide dismutase (SOD) [85,88], tiron [90], dimethylsulphoxide [91], mannitol, metal chelators [92] or catalase [84], to inhibit free radical levels. The generation of $\mathrm{O}^{2-}$ radicals, in particular, has been demonstrated by the ability of DEP to scavenge both exogenous [88] and endothelial-derived [93] $\mathrm{NO}$ in vitro, an effect that could be attenuated by addition of SOD.

A wide range of free-radical generating capacity is observed depending on the source of particulate $[94,95]$ and even supposedly similar particle types from relatively nearby areas within a city, or from the same site in different weather conditions, can make a sizeable difference to the free-radical potential $[89,96]$. It is often assumed that chemicals and metals adsorbed onto the particles surface drive the detrimental effects of air pollution. Certainly organic chemicals and reactive transition metals can initiate free redox cycling; however, interestingly, 'clean' carbon particles with significantly lower levels of the surface chemicals and metals (Figure 1D) can generate similar, if not greater, levels of free radicals than that of urban particulates of a similar size [Miller et AL., Unpublished Data] [86]. Therefore, surface components alone may not be able to predict the toxicity of different PM. As well as the innate ability of PM to generate free radicals themselves, in biological systems particles

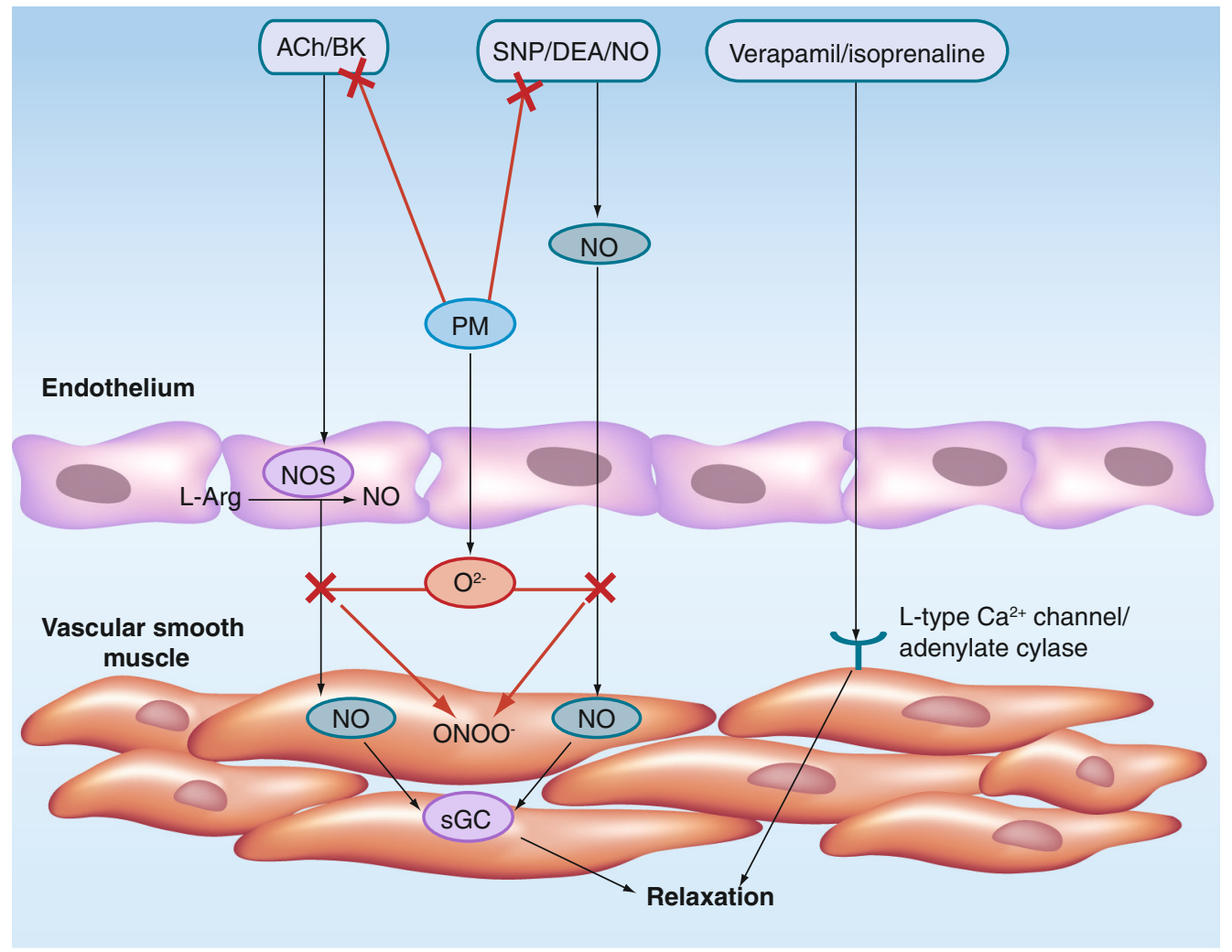

Figure 6. Methods by which different vasodilators can be used to establish the mechanism of vascular impairment to, for example, particulate matter. Impairment of responses to ACh or BK only suggests a site of action at the level of the endothelium, whereas impairment of all three types of vasodilator suggests impairment at the level of the vascular sooth muscle cells. Inhibition of ACh/BK and NO donors (e.g., SNP or DEA/NO, but not vasodilators acting directly on vascular smooth muscle cells (verapamil; or isoprenaline in many animal tissues), suggests selective impairment of NO-mediated vasodilatation, often attributed to scavenging of NO by oxygen free radicals such as $\mathrm{O}^{2-}$. This is often the pattern seen following exposure to PM (see Figure 4 ). The reaction of $\mathrm{O}^{2-}$ with $\mathrm{NO}$, produces the detrimental mediator, $\mathrm{ONOO}^{-}$, and leads to loss of many actions of NO (e.g., vasodilatation, inhibition of platelets, suppression of inflammation and inhibition of smooth muscle cell proliferation).

Ach: Acetylcholine; BK: Bradykinin; DEA/NO: DiethyleneNONOate; L-Arg: L-arginine; NO: Nitric oxide; NOS: Nitric oxide synthase; O: Superoxide; ONOO*: Peroxynitrite; PM: Particulate matter; sGC: Soluble GC; SNP: Sodium nitroprusside. 


\section{Review Miller, Shaw \& Langrish}

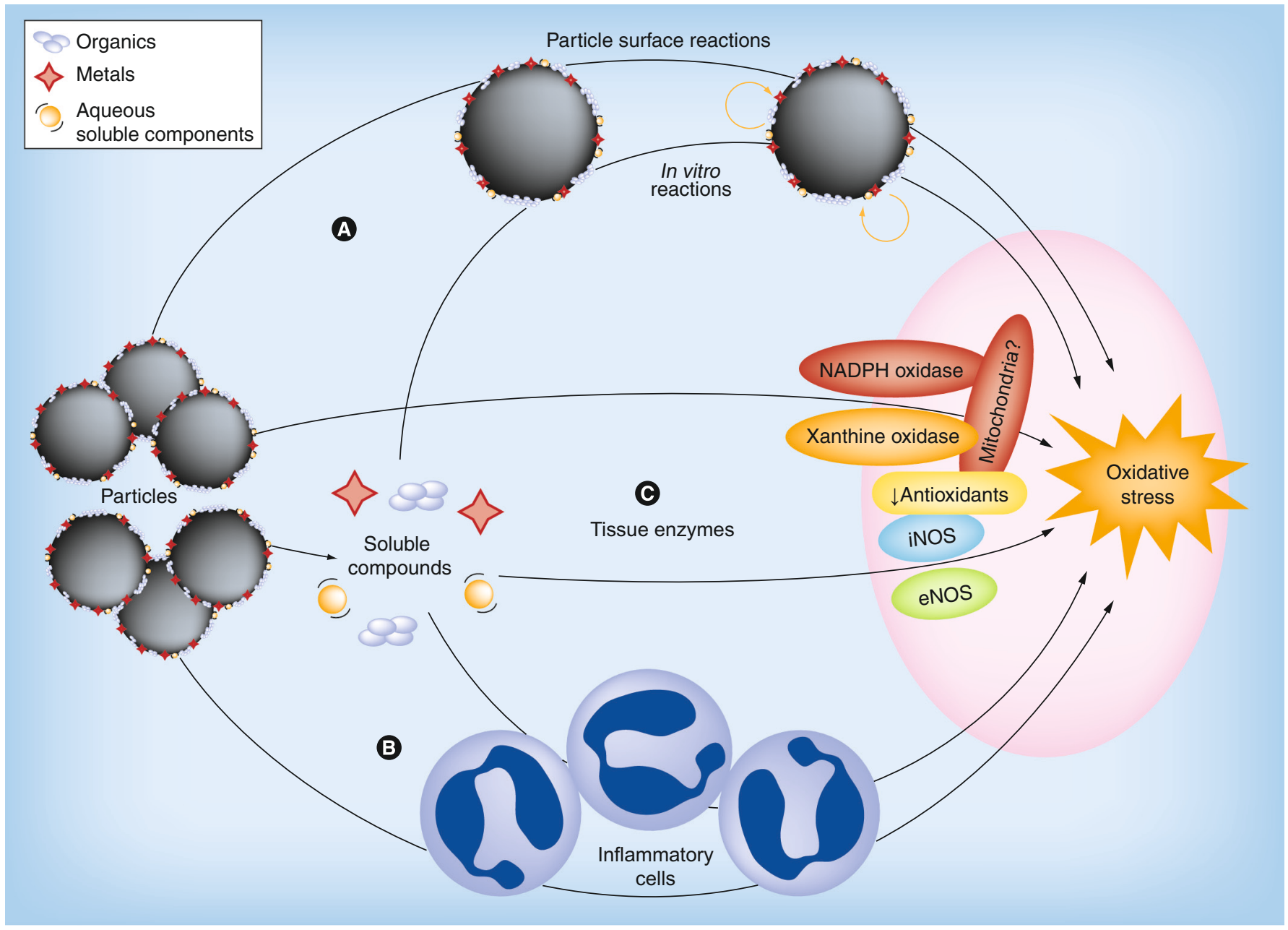

Figure 7. Different pathways through which contact between particulate matter and cells can induce cellular oxidative stress. (A) Innate generation of free radicals by particulate matter (PM) in the absence of biological tissue. Free radicals may be produced by redox reactions between different chemicals on the surface of the particulate. (B) Release of cytokines and oxidative mediators from PM-induced activation of inflammatory cells. (C) Free radical generation from interaction between PM and cells (e.g., from stimulation of enzymes, such as NADPH oxidase, xanthine oxidase, uncoupling of eNOS, iNOS, exacerbation of free radicals from mitochondrial inefficiency or depletion of antioxidant defences). These pathways may be stimulated by particulate itself or through release of soluble constituents of PM in biological fluids. Note, the pathways in this figure relate to basic cellular interactions (e.g., that of a translocated particle interacting with an endothelial cell) to particulates and do not include more complex pathways, such as neurohumoral interactions or accumulation of particles/particle constituents at specific sites (e.g., adipose tissue). eNOS: Endothelial nitric oxide synthase; iNOS: Inducible nitric oxide synthase.

are able to induce the cells/tissues to synthesize biologically-derived free radicals, adding to that produced directly by the particulate (FIGURE 7). Therefore, there are several ways that different components of PM can generate free radicals in biological systems.

\section{Particle-induced oxidative stress in cells \& animals \\ Particle-induced oxidative stress in cell cultures}

Despite the large number of potentially toxic chemicals in urban PM and the capacity for particles to generate oxidative stress, PM itself has little in the way of a direct cytotoxic action in cell cultures unless extremely high concentrations are used [97-101]. Nevertheless, PM, particularly DEP and their constituents, generate oxidative stress in a number of cell types crucial to the development or suppression of atheroma, including macrophages [102-104] and endothelial cells [98,105-108]. Therefore, the free-radical generating capacity of the PM has the ability to overcome cellular antioxidant defences. Certainly, stimulation of cultured endothelial cells with PM leads to compensatory changes in antioxidant systems, including upregulation of stress response genes such as HO-1 [98,107,109], tissue factor [110] and SOD [106].

While PM has the capacity to generate free radicals in the absence of cells, it is likely that an amplification of the PM-derived signal is 
required to tip the balance of the cell into oxidative stress. As such, stimulation of inflammatory pathways represents the most obvious amplification step. Accordingly, the ROS and inflammation pathways mediating the cellular response to PM are closely linked in both leucocytes and noninflammatory cells. Several sources of PM increase the expression of many proinflammatory molecules in both macrophages $[97,102,111-114]$ and endothelial cells $[107,110,115]$. For example, UFP can induce expression of ICAM-1, VCAM-1 [116], IL-6 and monocyte chemoattractant protein-1 in human endothelial cells [117] and the release of numerous proinflammatory cytokines, such as TNF- $\alpha$, in macrophages $[97,102,118,119]$. Expression of these cytokines is finely regulated by redox-sensitive transcription factors such as NF- $\kappa \mathrm{B}$, activator protein-1 $[102,107,118]$ and activation of the mitogen activated kinase JNK [106]. The dynamic interaction of inflammation and oxidative stress is demonstrated by the ability of NF- $\mathrm{BB}$ inhibitors [107] or antioxidants, such as ascorbate, desferrioxamine and $N$-acetylcysteine (NAC), to attenuate the release of these proinflammatory mediators $[98,116,120]$. Enzymatic sources of free radicals, such as nicotinamide adenine dinucleotide phosphate (NADPH) oxidase also contribute to free-radical production [121]. Thus, PM has the capacity to activate several cell types, inducing a proinflammatory phenotype that is consistent with progression of vascular disease. Generation of oxidative stress appears to mediate, possibly instigate, these actions and thus the interaction between inflammatory and oxidative pathways has potential to amplify the pulmonary effects of PM to an extent that could generate systemic effects (FIGURe 7).

\section{Particle-induced oxidative stress in single-organ models}

Cell function is strongly influenced by surrounding cells and their environment. This is particularly evident in the cardiovascular system where the endothelial cells finely regulate the function of circulating blood cells and the underlying smooth muscle cells. The use of isolated, but functioning, tissues provides a way of studying these paracrine actions in relatively simple preparations. Numerous groups have used such preparations to study the vascular mechanism of PM, using isolated blood vessels in an organ bath to study vessel contractility and the ability of the endothelium to influence vascular tone. These approaches have the advantage of studying vascular function in real time, as well as providing mechanistic insights through the application of pharmacological agents. However, the absence of neurohumoral inputs should not be forgotten, and comparison with in vivo data are needed in order to clarify the importance of these pathways in the overall physiological response. The main disadvantage from the perspective of particulates is the nonphysiological means of administration of PM: directly to the vessel, rather than via the lung. Thus, there is the caveat that the data obtained may have little relevance to real-world situations, as evidenced by the need to administer high concentrations of PM in order to observe the effects. Nevertheless, the similarity between these in vitro preparations and controlled exposures in man is striking (Figure 5) and even if coincidental, these in vitro studies provide proof-of-principle that particles have the capacity to directly alter vascular function should they translocate into the circulation.

Direct treatment of rodent aorta with PM from diesel [85,93] or motorcycle exhaust [122] promotes phenylephrine-induced vasoconstriction and inhibits vasodilatation to ACh. More recent studies have shown that the inhibitory response of DEP extends to NO-mediated vasodilators (endothelial $\mathrm{NO}$ and $\mathrm{NO}$ donor drugs), but does not act through impairment of soluble guanylatecyclase activity or other actions on vascular smooth muscle cells [88,123]. The inhibitory effect of these particulates can be at least partially reversed by coincubation with antioxidants such as SOD, trolox or NAC [85,88,122,124,125], although mannitol (a hydroxyl radical scavenger) was without effect [53]. This pattern of inhibition closely matches that of inhalation of whole DEP in man $[51,88]$ and these studies reinforce the hypothesis that PM impairs cardiovascular function through generation of $\mathrm{O}^{2-}$ free radicals.

While PM is able to inhibit vasodilation to NO donor drugs [88], the magnitude of this effect can be small or insignificant in contrast to that of agents that act through endothelial NOS [126,127]. Treatment with NOS inhibitors can reverse the proconstrictor effect of PM suggesting that either inducible NOS (iNOS) or uncoupling of endothelial NOS (eNOS) may contribute to vascular impairment ('uncoupling' of NOS is a term given to dysfunction of the enzyme leading to $\mathrm{O}^{2-}$, rather than $\mathrm{NO}$, formation) [126]. Similarly, PM may stimulate $\mathrm{O}^{2-}$ formation via NADPH oxidase [128]. Finally, a single study found that the PM-induced vascular dysfunction was reversed by dexamethasone, but not tempol or ascorbate, suggesting 
that the vascular effects of PM in vitro may also be via free radical-independent mechanisms (e.g., inflammatory pathways) (FIGURe 7) [123].

The composition of PM will likely account for some of the variability between studies, and the availability of tissue for isolated preparations allows testing of multiple types of PM. Several studies have tested vehicle exhaust particles, residual oil fly ash (ROFA; a metal-rich environmental PM) or PM extracts on isolated arteries to assess whether soluble chemicals on the particle mediate the vascular impairment. Compounds that are removed by aqueous or organic solvents both have the capacity to promote contraction and impair relaxation, often through ROS [53,124-127,129,130]. Thus, multiple constituents within PM can directly impair vascular function and studies are now required to address which are the most important components, initially in vitro and then in vivo and in man.

Briefly, PM can also affect the function of nonarterial tissue. Firstly, there is a suggestion that diesel exhaust may have a greater contractile effect on veins than arteries [126]. Perfusion of isolated hearts with carbon particles has been shown to increase heart rate, an effect that was attributed to increased release of catecholamines from myocardial nerve endings [131]. The direct effects of PM on the blood may be especially relevant if particles do translocate into the circulation. Several types of PM have a direct action on blood, promoting coagulation and platelet aggregation [132-135]. Treatment with a hydroxyl radical scavenger can partially inhibit some the effects of PM on fibrin-clot formation [136].

\section{Particle-induced oxidative stress in animal models}

The cardiovascular effects of PM in animal models

While cell cultures and isolated organs have provided useful mechanistic data, at present no single in vitro assay is able to predict in vivo toxicity. As such, animal models of health and disease are essential to fully understand the consequences of exposure to air pollution. Inhalation is the most physiological way to expose animals to air pollution; however, rodents are obligate nose breathers and a proportion of inhaled particles will be lost within the complex nasal passages of these animals, reducing the dose of PM that reaches the lungs. Pulmonary exposure to PM (in the absence of gases) can also be performed by instillation; a routine technique where suspensions of particulate (or their extracts) are given as a bolus into the trachea. Importantly, the cardiovascular effects of both routes of PM administration in animals are strikingly similar to that of controlled exposures in man; (e.g., altered vascular contractility, impaired vasodilation, increases in blood thrombogenecity/coagulability) [133] and an increased association between circulating inflammatory cells and the vascular wall [137].

In line with the alteration in the balance towards constriction over relaxation in isolated blood vessels, in vivo exposure to air pollution is associated with raised blood pressure [138-142] and changes in heart rate and in the ECG, most notably decreased heart rate variability [143]. These rapid changes in response to pulmonary exposure to PM are most likely the result of activation of the autonomic nervous system following stimulation of sensory receptors in the lung $[144,145]$. Autonomic activation may play a role in alteration of baroreceptor sensitivity $[146,147]$, providing an additional route by which PM can influence the response to vasodilators in vivo. Finally, in vivo models have recently revealed that exposure to PM has the ability to alter other aspects of the cardiovascular system, including angiogenesis [148], circulating stem cells [149] and important cardiovascular risk factors, such as hypercholesterolemia, obesity and diabetes [150-152].

PM \& oxidative stress in animal models

In light of the limited clinical data regarding the role of oxidative stress in the actions of PM in man, animal models have the greatest potential to explore these pathways in detail under physiological and pathophysiological conditions. Reassuringly, inhalation/instillation of urban PM promotes the response to vasoconstrictors and inhibits endothelium-dependent vasodilatation in healthy animals [123,153], hypertensive animals $[154,155]$ and animal models of atherosclerosis $[150,156,157]$. These effects occur in response to a single bolus instillation or prolonged inhalation (hours-months), are evident several hours after exposure and remain at least $24 \mathrm{~h}$ later. Unfortunately, it is difficult to make comparisons of the relative reactivity of different particulates due to differences in dose, route of administration, particle size and particle composition between different studies (see review by Moller et al. [158] for a comprehensive summary of these studies). Pretreatment/coadministration of free radical scavengers or other antioxidant compounds (e.g., SOD, NAC, tiron, cysteine prodrugs) prevents PM-induced vascular impairment $[159,160]$, suggesting that oxidative stress is an important mechanism in the cardiovascular 
actions of inhaled/instilled PM. A role for $\mathrm{O}^{2-}$ in the actions of PM is supported by impairment of, not only drugs that generate endothelial NO, but also vasodilators that generate $\mathrm{NO}$ through endothelium-independent means (e.g., NO donor drugs such as SNP) [126,157,159]. However, the magnitude of the inhibitory effect on responses to NO donors is smaller and less consistent $[126,153,161]$. This may simply be due to the localized release of $\mathrm{NO}$ from these compounds at distant sites to that of PM-derived free radicals (e.g., vascular smooth muscle cells compared with endothelial cells for SNP and ACh, respectively). Alternatively, the greater action of PM on endothelial-dependent relaxation, could be attributed to oxidation of cofactors for eNOS [159] or increases in the endogenous inhibitors of eNOS [162].

Another benefit of animal models is the greater availability of techniques to quantify oxidative stress. Systemic oxidative stress following pulmonary exposure to PM has been demonstrated by cell-permeable fluorescent compounds (e.g., tetranitro blue tetrazolium or dihydroethidium) [137,163], chemiluminescence $[157,164,165]$, nitrotyrosine staining $[166,167]$, thiobarbituric acid reactive substances (TBARS) $[164,168]$, trolox equivalent antioxidant capacity [160], tissue lipid peroxidation [169], urinary 8-isoprostanes or 8-OH-dG [170] and indirectly through CD36 staining $[170,171]$. Importantly, oxidative stress can be detected, not just in blood and urine but, in vascular tissue or atherosclerotic plaques from PM-exposed animals $[137,157,163,166-168,170,171]$. Furthermore, the buildup of oxidative stress is reflected in changes in antioxidant expression or activity, (e.g., HO-1, catalase, SOD-2, GSTs, NADPH quinoneoxidoreductase 1, p45-NFE2-related transcription factor-2) $[165,167,172,173]$.

Several cellular sources have been proposed to account for free radical generation, including NADPH oxidase [150,157,174], uncoupling of eNOS [159] and iNOS induction $[166,167,175]$.Importantly, administration of exogenous antioxidant compounds (e.g., tempol, NADPH oxidase inhibitors and iNOS inhibitors) have the capacity to reverse some aspects of the PM-induced cardiovascular impairment $[159,160,171,176,177]$. It has recently been proposed that oxidized phosphorylcholine may act as a mediator of the oxidative effects of PM, potentially carrying this signal from the lung to the cardiovascular system [174]. Interestingly, both pre- and post-natal PM increased levels of myocardial lipid peroxidation and isoprostanes in mice [169], again suggesting that the oxidative effects of PM are long-lived and potentially 'carried' by some means to subsequent generations.

Animal studies often use relatively high doses of PM to overcome the difficulties of chronic exposure regimes. By contrast, Wan et al. showed that 10 weeks inhalation of fine PM at levels representative of those within the National Ambient Air Quality Standards increased oxidative stress in the aortic endothelium of mice [163], demonstrating that even in situations where PM recommendations are not breeched (as is the case in many cities worldwide), even low levels of PM represent a hazard. Overall, the studies in healthy animals point to a complex mechanism of action of PM, and several means by which inhaled particulates can generate oxidative stress. Pulmonary exposure to PM has the capacity to have widespread systemic effects, even in healthy animals with good levels of antioxidant defence.

PM \& oxidative stress in animal models of disease PM clearly has the ability to impair vascular function in healthy animals, although the doses of PM required are often high or for prolonged periods. Thus, there is an assumption that healthy animals may understate the potential risks of inhaled PM in the real world where individuals are exposed to additional stressors or have a variable degree of health. Subsequently, many researchers have opted to investigate the effects of PM in disease models, or in animals challenged in additional ways (e.g., existing lung inflammation or exposure to a mixture of air pollutants).

In terms of cardiovascular stress, the actions of PM have largely focused on two conditions, atherosclerosis (see the 'PM \& oxidative stress in animal models of atherosclerosis' section) and hypertension. Hypertension can be induced experimentally (prolonged infusion of angiotensin II) or by using rodents with an altered genetic background (spontaneously hypertensive rats [SHRs]). In both these models, urban PM and DEP have a tendency to raise blood pressure by $7-30 \mathrm{mmHg}[133,138,154]$. Alterations in autonomic activity may augment these hypertensive actions [145]. PM can also increase the degree of cardiac remodeling in response to the high blood pressure induced by angiotensin-II infusion [154].

It is difficult to address whether the effects of PM are greater in hypertensive animals than their healthy counterparts due to the differences in baseline blood pressure and existing impairment of the vasculature. For example, inhalation of diesel exhaust had little effect on the 
expression of antioxidant expression in the hearts of SHRs, but decreased levels in healthy animals to similar levels of that already existing in SHRs, suggesting that expression of these genes may already be maximally changed in SHRs [178]. Nevertheless, platelet aggregation ex vivo and blood clotting in vivo was increased following DEP inhalation [133], an effect that was particularly pronounced in hypertensive animals. Only a single study found that the vascular effects of PM were significant in hypertensive animals, but not healthy animals [177]. Theoretically, though, any degree of further vascular impairment/increase in blood pressure may be enough to trigger a plaque rupture or heart failure in a cardiovascular system that is already under significant stress. The complexity of coronary events is difficult to represent in animal models. Myocardial ischemia and infarction can be explored in rodents by surgical occlusion of a coronary artery. In this model, pulmonary exposure of PM prior to ischemia doubled the size of infarction of the myocardium of rats, with an increase in inflammatory cell infiltration and oxidative stress in the infarcted region [155].

Whether or not PM exerts a greater effect on cardiovascular function in these models, it is clear that oxidative stress contributes to the actions of PM. In two very detailed studies, Rajagopalan's group showed that PM inhalation increased blood pressure in angiotensin-IIinfused rats. The effect was associated with raised levels of aortic $\mathrm{O}^{2-}$ and eNOS uncoupling, by a mechanism that involved depletion of tetrahydrobiopterin $\left(\mathrm{BH}_{4}\right.$; a key cofactor for eNOS), stimulation of NADPH oxidase and rho-mediated pathways $[154,177]$. Which of these pathways mediate the actions of the PM-induced effects on the heart and which actually initiate them remains to be established.

PM \& oxidative stress in animal models of atherosclerosis

As discussed earlier, people living in areas of high air pollution, or close to a major road, have an increased atherosclerotic burden compared with those living in less polluted areas. Prior to these studies Suwa et al. showed that 4 weeks of repeated instillation of (high dose) PM lead to an increase in the extent of atherosclerosis in the arteries of rabbits [179]. Since this time there have been a host of studies, predominantly using atherosclerosis-prone ApoE knockout $\left(\mathrm{ApoE}^{-/-}\right)$ mice, showing that inhalation/instillation of urban PM, gasoline exhaust, diesel exhaust or DEP increases the size of atherosclerosis and promotes the development of plaques with an unstable phenotype (expertly reviewed in $[180,181])$. A host of mechanisms have been proposed to contribute to the proatherosclerotic effect of PM, including inflammation of the vascular wall $[172,179,182]$, endothelial dysfunction $[157,166]$, enhanced expression of tissue factor [100], upregulation of matrix metalloproteinases $[167,176]$, fragmentation of subendothelial plaque layers [183], increased expression of iNOS [157,171] and increased plasma levels of heat shock protein 70 [184]. Oxidative stress has the potential to connect all these mechanisms, and there is now a solid body of research to firmly implicate this as a key mechanism in the proatherosclerotic effects of PM.

Numerous studies have found increased levels of oxidative stress in the plaques of PM-exposed ApoE $^{-/}$mice $[157,166,167,170]$. The ability of PM to impair endothelial function and promote leucocyte adherence to arteries (see above) suggests that PM may play a significant role in the early stages of atherogenesis. Alternatively, the early atherosclerotic effects of PM may occur within the vascular lumen. Oxidation of LDL in the blood significantly promotes the uptake of lipids into the vascular wall and PM has been shown to oxidize LDL in vitro [185] and in vivo [186]. A mixed diesel-gasoline exposure in $\mathrm{ApoE}^{-/-}$mice was shown both to increase oxidized LDL and result in the progression of atherosclerosis through increased expression of lectin-like oxLDL receptors (LOX-1) [168]. Of particular interest is the novel observation that PM decreased the ability of HDL to protect LDL from oxidation [173]. The effect was particularly evident following ultrafine PM exposure, rather than fine PM and highlights once again that the oxidative effects of PM may be through impairment of antioxidant function, rather than direct free-radical generation by PM itself. Finally, it is worth noting that in one study, inhaled CAPs increased the vasoconstrictor responses and impaired ACh vasodilatation in $\mathrm{ApoE}^{-/-}$, but only in groups fed high-fat diets and not those on regular chow [166]. Thus, the interaction of lipids and air pollutants may have notable functional consequences, which raises the question as to whether air pollution has synergistic actions with other cardiovascular risk factors that may promote atherosclerosis (e.g., long-term increases in blood pressure, smoking, diabetes, chronic inflammatory conditions).

In the interests of balance, we should emphasize that it is not possible to say whether this enhanced oxidative stress is directly related to 
PM-induced changes that lead to the alteration of plaque morphology, or simply due to the presence of plaques at a later stage of their development. In favor of the latter, oral administration of the antioxidant tempol during gasoline exposure prevented the gasoline-induced vascular oxidative stress, without affecting PM-induced changes in vascular gene expression [176]. Similarly, filtering particles from diesel exhaust tended to decrease levels of thiobarbituric acid reactive substances in aortic tissue without significantly affecting the ability of the emissions to alter plaque composition [187]. Thus, there may be a degree of dissociation between vascular oxidative stress and the proatherosclerotic effects of air pollution.

\section{Composition of PM \& oxidative stress in} animal models

An important topic in this area is which constituents of air pollution mediate the cardiovascular actions of air pollution, although at present this issue has only been investigated in a limited number of studies with relatively rudimentary fractionation of pollutants. Animal models allow greater flexibility in the type of exposure to address this question (e.g., instillation allows for the testing of DEP components that have been fractionated in solvents that would not be appropriate for human administration). Both the epidemiology and controlled exposures in man suggest that the particulate components of air pollution are the major detrimental constituent of air pollution, rather than the gaseous and volatile liquid copollutants. In the interests of balance, there is evidence from animal models that the gaseous constituents mediate a proportion of the cardiovascular actions. For example, exposure of only gases, by removing particles through filtration of vehicle exhausts, has been shown to have similar effects to that of 'whole' exposures (PM and gases) on some cardiovascular parameters $[167,187]$. However, similar to clinical studies [53,188], other studies have shown that removal of the particulate fraction, abolishes many of the cardiovascular effects of emissions $[165,168]$. Overall, it is more likely that gaseous emissions in vehicle exhausts potentiate some of the particle effects [189] and thus exacerbate the atherogenic effect of urban PM.

Identification of the harmful constituents of particulate air pollution would be advantageous in the design of novel fuels or technologies to reduce the health effects associated with their use. However, the chemical composition of urban PM or vehicle exhaust is vast and highly variable; dependent on fuel used, combustion conditions/engine characteristics and environmental conditions $[89,94-96,190,191]$. It is assumed, but far from established, that it is the organic chemicals and/or transitional metals on the surface of the particles that are responsible for their biological actions. This hypothesis can be tested by exposing animals to 'clean' carbon UFPs, such as carbon black, and 'inert' noncarbon UFPs, such as titanium dioxide. Interestingly, these particles are not entirely without effect, and have been shown to raise blood pressure [192], increase heart rate [131,193], alter vasodilator responses $[156,161,194]$ and increase oxidative stress in circulating neutrophils [195]. Nevertheless, with a few exceptions [161], the magnitude of the effects of 'clean' particles is small in comparison with that of environmental PM or DEP $[123,156,165]$. Thus, it does appear that surface chemicals are important to the cardiovascular effects of urban PM, and identification and removal of key components is the subject of current research.

\section{Summary \& conclusion}

Particulate air pollution has significant detrimental effects on the cardiovascular system and is linked to substantial increases in cardiovascular events, morbidity and mortality. Several different types of PM have been shown to exert an oxidative insult alone, in cell cultures, in isolated tissues, in animal models and evidence is now beginning to emerge in man also. The mechanism of effect remains to be established, but may be through a combined oxidative insult from PM itself, stimulation of ROS-generating enzymes in the vascular endothelium and indirectly through activation of inflammatory cells and neurohumoral pathways. At present it is unclear as to whether PM-induced oxidative stress underlies the cardiovascular effects of inhaled particles, or is a consequence of disease progression. Nevertheless, it is almost certain that PM-induced oxidative stress will exacerbate the detrimental cardiovascular effects of PM. Identification and removal of the detrimental constituents of PM that generate free radicals may represent a way to limit the harmful effects of air pollution.

\section{Future perspective}

Air pollution exposure is now considered as a risk factor for cardiovascular diseases. Although the absolute increase in risk associated with exposure is modest in comparison with other risk factors, such as poor diet, the ubiquitous nature of air pollution exposure means that the whole population is affected. Indeed, at the population-level 
it is arguably the most important risk factor for acute cardiovascular events [23]. Importantly, air pollution exposure is entirely modifiable and it is clear that in order to reduce this risk, our primary aim should be to limit exposure. There is epidemiological evidence to support such a strategy: following the banning of the sale of bituminous coal in Dublin, Ireland in the early 1990s, air quality improved almost overnight and with a corresponding fall in the incidence of cardiovascular events [196]. Cigarette smoke is another complex air pollutant, but it is notable that it shares many similar groups of reactive organic chemical species. Following the introduction of smoking bans in public places in many developed countries within the last decade, there has been a large reduction in the incidence of acute myocardial infarction among the general public $[197,198]$. The challenge now is: how we can effectively implement interventions that could reduce levels of harmful PM. This is especially pertinent in developing countries where rapid economic development means an ever-increasing reliance on fossil fuels for domestic use, transport and industry, accompanied by the use of old and inefficient vehicles.

If it is not possible, at least in the short-term, to reduce the population exposure to PM air pollution, alternative interventions need to be considered. It has been argued that in order to design specific interventions to protect the public from the adverse effects of inhaled PM we require a greater understanding of the pathways involved. Our understanding of the later pathophysiological effects of PM air pollution is actually good, what is lacking is the intermediate stages of the processes: how are the effects of inhaled PM transferred and amplified to an extent that they can cause significant damage to the cardiovascular system. However, this missing step may not be of relevant if oxidative stress plays a crucial role at multiple sites of the pathway, then there is potential to develop therapies that act at one or more of these sites.

There is a noticeable deficit in studies testing the ability of pharmacological therapies to ameliorate the effects of air pollution in man. A few small epidemiological and panel studies have suggested that use of statins [199] or $\beta$-blocker drugs $[49,200]$ can limit the effects of PM, although in specific populations and with limited end points investigated. Nevertheless, bearing in mind the slow progress of legislative changes to reduce combustion-derived PM, it is useful to consider whether current medical therapies may be useful adjunct intervention. The obvious pharmacological intervention would be to use antioxidants to eliminate significant oxidative stress. While there is now good evidence from animal models that a range of antioxidant compounds can prevent the effects of PM both in vitro and in vivo (see above), there is no such evidence in man. This is perhaps just a reflection of the difficulty in studying oxidative stress in man; however, the enthusiasm for such an approach to prevent the cardiovascular actions of PM is dented by the poor outcome data from clinical trials of antioxidant therapy in cardiovascular diseases in general. Nevertheless, it would be unwise to dismiss the potential therapeutic benefits of antioxidant therapies, especially where there is clear evidence for free radical-mediated pathways, as is the case with air pollution. There is a need for better-designed antioxidant therapies that have the capacity to specifically reach the locations under attack from the oxidative actions of PM (endothelial cells for example), or to provide antioxidants that can be readily recycled to replenish key endogenous antioxidant pools. Alternatively, consideration should be given to other classes of pharmacological agents, for example those that inhibit enzymatic sources of free radicals activated by PM (e.g., NADPH oxidase), or block the sensory receptors in the lung that could mediate the cardiovascular effects of PM via the autonomic nervous system.

It is interesting that, in general, the effects of PM exposure do not appear to be greater in patients with, and animal models of, cardiovascular disease compared with their healthy counterparts. In all likelihood, this can be explained by the presence of existing vascular disease, limiting the potential for inhaled PM to exert a further adverse effect. However, in the clinical scenario patients are usually on optimal medical therapy, which includes a number of medications that target the pathways known to exacerbate cardiovascular disease which may account for the reduced effects seen [200]. Statins are now the first-line treatment for hypercholesterolemia and atherosclerotic diseases, and the combined action of these drugs to lower plasma cholesterol and exert an anti-inflammatory action would suggest that these drugs may afford some degree of protection from the actions of air pollution mediated by these pathways. Indeed, there is some preliminary evidence to suggest statins may confer a benefit in limiting oxidative stress following PM exposure in man in patients with impaired endogenous antioxidant pathways [199]. Similarly, the antiplatelet and anti-inflammatory properties of aspirin, may also combat the effects 
of air pollution and $\beta$-blocker drugs may limit the neurohumoral responses to air pollution exposure. These observations raise questions as to whether we are underestimating the actions of air pollution in patients taking such medication, or more pressingly, are we overlooking readily available ways to limit the consequences of air pollution in those patients who are not prescribed these drugs.

From an economic point of view it is beneficial to target interventions towards high-risk groups, as is currently the normal practice with statins in the treatment of hypercholesterolemia. This could be with regards to targeting specific cardiovascular conditions, subsets of patients or even the genotypes of potentially high-risk groups (see the effect of statins in GST null populations; [199]). Given the inherent costs in any pharmacological intervention, a more appropriate intervention is to reduce the exposure to PM air pollution of those thought to be at highest risk. There is limited evidence that use of personal respiratory protection in the form of a facemask can reduce the adverse effects of exposure to PM [201,202], although it remains to be seen if such an intervention can reduce the incidence of acute cardiovascular events. While such an intervention would be cheap and readily achievable

\section{Executive summary}

\section{Air pollution \& cardiovascular epidemiology}

- Urban air pollution is estimated to cause approximately 800,000 deaths per year worldwide, over and above conventional risk factors.

- The associations between air pollution and cardiovascular disease are strongest for airborne particulate matter (PM), rather than gaseous copollutants.

- Urban air pollution and vehicle emissions are rich in ultrafine particles. These particles are believed to be especially harmful due to their ability to penetrate deep into the lungs (and perhaps the circulation) and carry large amounts of toxic chemicals on their surface.

\section{Controlled exposure of air pollutants}

- Exposure to urban PM or vehicle exhaust, in man, promotes vasoconstriction/impairs vasodilatation, raises blood pressure, increases thrombosis/decreases fibrinolysis, increases the activity of circulating inflammatory cells and exacerbates cardiac ischemia.

\section{Air pollution \& oxidative stress}

- The underlying mechanism for the cardiovascular effects of air pollution is unknown. Results from preclinical studies suggest oxidative stress may be a mechanism to link together inhaled PM and the subsequent cardiovascular dysfunction.

\section{Epidemiology \& clinical evidence}

- Controlled exposures of diesel exhaust show an impairment of nitric oxide-mediated vasodilatation, a pattern suggestive of super oxide generation in the vasculature.

- There are a limited number of epidemiology studies investigating oxidative stress effects of air pollution; however, the majority link PM exposure to oxidation of proteins/lipids and changes in antioxidant pathways.

\section{Particles as a direct source of free radicals}

- Urban PM, diesel exhaust particulate and other carbon-based particles generate super oxide free radicals in physiological solutions in the absence of tissue.

- Levels of free-radical generation depend on the size, surface area and the chemical composition of the particulate.

\section{Particle-induced oxidative stress in cell cultures}

- Direct exposure of cells to particles has surprisingly limited cytotoxicity. However, both urban PM and diesel exhaust particulate promote a proinflammatory phenotype in macrophages and endothelial cells, via interaction with oxidative stress pathways.

\section{Particle-induced oxidative stress in single-organ models}

- Direct exposure of isolated blood vessels with PM impairs vascular function in a similar pattern to that of clinical exposures.

- The vascular impairment is mediated by generation of free radicals from cellular enzymes following stimulation of tissues by PM and from the chemical constituents of PM itself.

\section{Particle-induced oxidative stress in animal models}

- There is consistent evidence for the role of free radicals in the vascular impairment, hypertensive and atherosclerotic actions of PM in healthy animals and disease models.

- PM may generate free radicals by stimulation of NADPH oxidase, inducible NOS induction or uncoupling of endothelial NOS.

- Many of the effects of PM can be limited by coadministration of free radical scavengers or antioxidants.

\section{Summary \& conclusion}

- There is strong evidence for the role of free radicals in the detrimental cardiovascular actions of inhaled PM. Free radical pathways are likely to contribute to multiple steps of the mechanism by which the pulmonary effects of inhaled PM are transmitted to the cardiovascular system.

- The ability of pharmacological compounds to limit the cardiovascular effects of air pollution remains to be tested. At present interventions that reduce particulate emissions into the environment represent the primary means to limit the biological effects of air pollution. 
in the short-term, it is unlikely to be more than a temporary intervention until more stringent environmental controls can be implemented.

Despite the potential in the above interventions, the single most effective way to limit the health effects of air pollution in the general population is undoubtedly to reduce harmful emissions in the first place. The health effects of air pollution are strongly linked to the fine (and ultrafine) components, from traffic and industrial processes that burn fossil fuels. There is already evidence that reducing PM emissions from diesel engines by the use of a retrofit particle trap can abolish the adverse vascular effects of diesel exhaust exposure [188]. Alternatively, modification of fuels and engine technology to ensure more complete combustion, such as the use of fuel additives like cerium oxide, can reduce PM emissions. This article highlights the importance of the composition of the emissions, and PM itself, and wide variation in the cardiovascular effects of different types of PM [76,203]. Identification of the detrimental physiochemical properties of airborne PM will lead to improvements in fuel and engine technologies to limit the presence of these chemicals from emissions. A combined scientific and clinical approach using complementary techniques is now needed to establish the potential of these interventions in reducing the health effects of air pollution, paying specific attention to the whether these interventions can prevent the oxidative-stress driven actions of inhaled particles.

\section{Financial \& competing interests disclosure \\ All authors are funded by a British Heart Foundation Programme (RG/05/003) grant. MR Miller is also funded by a British Heart Foundation Project grant (PG/10/042/28388). The authors also acknowledge the support of the British Heart Foundation Centre of Research Excellence award. The authors have no other relevant affiliations or financial involvement with any organization or entity with a financial interest in or financial conflict with the subject matter or materials discussed in the manuscript apart from those disclosed. \\ No writing assistance was utilized in the production of this manuscript.}

\section{References}

Papers of special note have been highlighted as:

- of interest

1. Brook RD, Rajagopalan S, Pope CA 3rd et al. Particulate matter air pollution and cardiovascular disease: an update to the scientific statement from the American Heart Association. Circulation 121(21), 2331-2378 (2010).

- The most comprehensive review of the evidence to date from epidemiological, clinical and preclinical studies.

2. Donaldson K, Stone V, Clouter A, Renwick L, MacNee W. Ultrafine particles. Occup. Environ. Med. 58(3), 211-216 (2001).

3. Aitken RJ, Chaudhry MQ, Boxall AB, Hull M. Manufacture and use of nanomaterials: current status in the UK and global trends. Occup. Med. (Lond.). 56(5), 300-306 (2006).

4. Zheng M, Cass GR, Ke L et al. Source apportionment of daily fine particulate matter at Jefferson Street, Atlanta, GA, during summer and winter. J. Air Waste Manage. Assoc. 57(2), 228-242 (2007).

5. Scheepers PT, Bos RP. Combustion of diesel fuel from a toxicological perspective. II. Toxicity. Int. Arch. Occup. Environ. Health 64(3), 163-177 (1992).

6. Scheepers PT, Bos RP. Combustion of diesel fuel from a toxicological perspective. I. Origin of incomplete combustion products. Int. Arch. Occup. Environ. Health 64(3), 149-161 (1992).
7. Sydbom A, Blomberg A, Parnia S, Stenfors N, Sandstrom T, Dahlen SE. Health effects of diesel exhaust emissions. Eur. Respir. J. 17(4), 733-746 (2001).

8. Franchini M, Mannucci PM. Thrombogenicity and cardiovascular effects of ambient air pollution. Blood 118(9), 2405-2412 (2011)

9. Gill EA, Curl CL, Adar SD et al. Air pollution and cardiovascular disease in the multi-ethnic study of atherosclerosis. Prog. Cardiovasc. Dis. 53(5), 353-360 (2011)

10. Mustafic H, Jabre P, Caussin C et al. Main air pollutants and myocardial infarction: a systematic review and meta-analysis. JAMA 307(7), 713-721 (2012).

11. Dockery DW, Pope CA 3rd, Xu X et al. An association between air pollution and mortality in six U.S. cities. N. Engl. J. Med. 329(24), 1753-1759 (1993).

12. Laden F, Neas LM, Dockery DW, Schwartz J. Association of fine particulate matter from different sources with daily mortality in six U.S. cities. Environ. Health Perspect. 108(10), 941-947 (2000).

13. Pope CA 3rd, Burnett RT, Thun MJ et al. Lung cancer, cardiopulmonary mortality, and long-term exposure to fine particulate air pollution. JAMA 287(9), 1132-1141 (2002).

14. Analitis A, Katsouyanni K, Dimakopoulou $\mathrm{K}$ et al. Short-term effects of ambient particles on cardiovascular and respiratory mortality. Epidemiology 17(2), 230-233 (2006).

15. Dominici F, McDermott A, Zeger SL, Samet JM. Airborne particulate matter and mortality: timescale effects in four US cities. Am. J. Epidemiol. 157(12), 1055-1065 (2003).

16. Katsouyanni K. Ambient air pollution and health. Br. Med. Bull. 68, 143-156 (2003).

17. Le Tertre A, Medina S, Samoli E et al. Short-term effects of particulate air pollution on cardiovascular diseases in eight European cities. J. Epidemiol. Community Health 56(10), 773-779 (2002).

18. Omori T, Fujimoto G, Yoshimura I, Nitta H, Ono M. Effects of particulate matter on daily mortality in 13 Japanese cities. J. Epidemiol. 13(6), 314-322 (2003).

19. Ostro B, Broadwin R, Green S, Feng WY, Lipsett M. Fine particulate air pollution and mortality in nine California counties: results from CALFINE. Environ. Health Perspect. 114(1), 29-33 (2006).

20. Zanobetti A, Schwartz J. The effect of fine and coarse particulate air pollution on mortality: a national analysis. Environ. Health Perspect. 117(6), 898-903 (2009).

21. Peters A, Dockery DW, Muller JE, Mittleman MA. Increased particulate air pollution and the triggering of myocardial infarction. Circulation 103(23), 2810-2815 (2001). 
22. Bhaskaran K, Hajat S, Armstrong B et al. The effects of hourly differences in air pollution on the risk of myocardial infarction: case crossover analysis of the MINAP database. BMJ 343, D5531 (2011).

23. Nawrot TS, Perez L, Kunzli N, Munters E, Nemery B. Public health importance of triggers of myocardial infarction: a comparative risk assessment. Lancet 377(9767), 732-740 (2011).

24. Libby P. Inflammation in atherosclerosis. Nature 420 (6917), 868-874 (2002).

25. Ross R. Atherosclerosis - an inflammatory disease. N. Engl. J. Med 340(2), 115-126 (1999).

26. Davignon J, Ganz P. Role of endothelial dysfunction in atherosclerosis. Circulation 109(23 Suppl. 1), III27- III32 (2004).

27. Mills NL, Donaldson K, Hadoke PW et al. Adverse cardiovascular effects of air pollution. Nat. Clin. Pract. Cardiovasc. Med. 6(1), 36-44 (2009).

- A clear and concise summary of acute cardiovascular effects of particulate matter (PM) and potential effector pathways.

28. Seaton A, MacNee W, Donaldson K, Godden D. Particulate air pollution and acute health effects. Lancet 345 (8943), 176-178 (1995).

29. Geiser M, Kreyling WG. Deposition and biokinetics of inhaled nanoparticles. Part. Fibre Toxicol. 7, 2 (2010).

30. Elder A, Oberdorster G. Translocation and effects of ultrafine particles outside of the lung. Clin. Occup. Environ. Med. 5(4), 785-796 (2006).

31. Schmid O, Moller W, Semmler-Behnke M et al. Dosimetry and toxicology of inhaled ultrafine particles. Biomarkers 14(Suppl. 1), 67-73 (2009).

32. Furuyama A, Kanno S, Kobayashi T, Hirano S. Extrapulmonary translocation of intratracheally instilled fine and ultrafine particles via direct and alveolar macrophageassociated routes. Arch. Toxicol. 83(5), 429-437 (2009).

33. Langrish J, Frampton M, Blomberg A. Human exposure studies. In: Cardiovascular Effects of Inhaled Ultrafine and Nanosized Particles. Cassee F, Mills N, Newby D (Eds). J Wiley and Sons Inc., NJ, USA, 217-239 (2011).

34. Brook RD, Brook JR, Urch B, Vincent R, Rajagopalan S, Silverman F. Inhalation of fine particulate air pollution and ozone causes acute arterial vasoconstriction in healthy adults. Circulation 105(13), 1534-1536 (2002).

35. Brook RD, Bard RL, Burnett RT et al. Differences in blood pressure and vascular responses associated with ambient fine particulate matter exposures measured at the personal versus community level. Occup. Environ. Med. 68(3), 224-230 (2011).

36. Peretz A, Sullivan JH, Leotta DF et al. Diesel exhaust inhalation elicits acute vasoconstriction in vivo. Environ. Health Perspect. 116(7), 937-942 (2008).

37. Lundback M, Mills NL, Lucking A et al. Experimental exposure to diesel exhaust increases arterial stiffness in man. Part. Fibre Toxicol. 6, 7 (2009).

38. Urch B, Silverman F, Corey P et al. Acute blood pressure responses in healthy adults during controlled air pollution exposures. Environ. Health Perspect. 113(8), 1052-1055 (2005).

39. Devlin RB, Ghio AJ, Kehrl H, Sanders G, Cascio W. Elderly humans exposed to concentrated air pollution particles have decreased heart rate variability. Eur. Respir. J. Suppl. 40, 76S-80S (2003).

40. Gong H Jr, Linn WS, Clark KW et al. Exposures of healthy and asthmatic volunteers to concentrated ambient ultrafine particles in Los Angeles. Inhal. Toxicol. 20(6), 533-545 (2008).

41. Gong H Jr, Linn WS, Sioutas C et al. Controlled exposures of healthy and asthmatic volunteers to concentrated ambient fine particles in Los Angeles. Inhal. Toxicol. 15(4), 305-325 (2003).

42. Gong H, Linn WS, Terrell SL et al. Exposures of elderly volunteers with and without chronic obstructive pulmonary disease (COPD) to concentrated ambient fine particulate pollution. Inhal. Toxicol. 16(11-12), 731-744 (2004).

43. Mills NL, Finlayson AE, Gonzalez MC et al. Diesel exhaust inhalation does not affect heart rhythm or heart rate variability. Heart 97(7), 544-550 (2011).

44. Mills NL, Tornqvist H, Gonzalez MC et al. Ischemic and thrombotic effects of dilute diesel-exhaust inhalation in men with coronary heart disease. N. Engl. J. Med. 357(11), 1075-1082 (2007).

45. Chuang KJ, Coull BA, Zanobetti A et al. Particulate air pollution as a risk factor for ST-segment depression in patients with coronary artery disease. Circulation 118(13), 1314-1320 (2008).

46. Gold DR, Litonjua AA, Zanobetti A et al. Air pollution and ST-segment depression in elderly subjects. Environ. Health Perspect. 113(7), 883-887 (2005).

47. Lanki T, de Hartog JJ, Heinrich J et al. Can we identify sources of fine particles responsible for exercise-induced ischemia on days with elevated air pollution? The ULTRA study. Environ. Health Perspect. 114(5), 655-660 (2006).

48. Lanki T, Hoek G, Timonen KL et al. Hourly variation in fine particle exposure is associated with transiently increased risk of ST segment depression. Occup. Environ. Med. 65(11), 782-786 (2008)

49. Pekkanen J, Peters A, Hoek G et al. Particulate air pollution and risk of ST-segment depression during repeated submaximal exercise tests among subjects with coronary heart disease: the exposure and risk assessment for fine and ultrafine particles in ambient air (ULTRA) study. Circulation 106(8), 933-938 (2002).

50. Brook RD, Urch B, Dvonch JT et al. Insights into the mechanisms and mediators of the effects of air pollution exposure on blood pressure and vascular function in healthy humans. Hypertension 54(3), 659-667 (2009).

51. Mills NL, Tornqvist H, Robinson SD et al. Diesel exhaust inhalation causes vascular dysfunction and impaired endogenous fibrinolysis. Circulation 112(25), 3930-3936 (2005).

52. Tornqvist H, Mills NL, Gonzalez M et al. Persistent endothelial dysfunction in humans after diesel exhaust inhalation. Am. J. Respir. Crit. Care Med. 176(4), 395-400 (2007).

53. Mills NL, Miller MR, Lucking AJ et al. Combustion-derived nanoparticulate induces the adverse vascular effects of diesel exhaust inhalation. Eur. Heart J. 32(21), 2660-2671 (2011).

- Data from our own group using both clinical and preclinical approaches to address which constituents of diesel exhaust are responsible for the vascular impairment of the exposure.

54. Lucking AJ, Lundback M, Mills NL et al. Diesel exhaust inhalation increases thrombus formation in man. Eur. Heart J. 29(24), 3043-3051 (2008).

55. Hoffmann B, Moebus S, Mohlenkamp S et al. Residential exposure to traffic is associated with coronary atherosclerosis. Circulation 116(5), 489-496 (2007)

56. Kunzli N, Jerrett M, Mack WJ et al. Ambient air pollution and atherosclerosis in Los Angeles. Environ. Health Perspect. 113(2), 201-206 (2005).

57. Bauer M, Moebus S, Mohlenkamp S et al. Urban particulate matter air pollution is associated with subclinical atherosclerosis: results from the HNR (Heinz Nixdorf Recall) study. J. Am. Coll. Cardiol. 56(22), 1803-1808 (2010).

58. Kunzli N, Jerrett M, Garcia-Esteban R et al. Ambient air pollution and the progression of atherosclerosis in adults. PLoS ONE 5(2), e9096 (2010). 
59. Brown DM, Donaldson K, Borm PJ et al. Calcium and ROS-mediated activation of transcription factors and TNF- $\alpha$ cytokine gene expression in macrophages exposed to ultrafine particles. Am. J. Physiol. 286(2), L344-L353 (2004).

60. Donaldson K, Mills N, MacNee W, Robinson $S$, Newby D. Role of inflammation in cardiopulmonary health effects of PM. Toxicol. Appl. Pharmacol. 207(Suppl. 2), 483-488 (2005).

61. Nel AE, Diaz-Sanchez D, Li N. The role of particulate pollutants in pulmonary inflammation and asthma: evidence for the involvement of organic chemicals and oxidative stress. Curr. Opin. Pulm. Med. 7(1), 20-26 (2001).

62. Lim KG, Mottram C. The use of fraction of exhaled nitric oxide in pulmonary practice. Chest 133(5), 1232-1242 (2008).

63. Delfino RJ, Staimer N, Tjoa T et al. Associations of primary and secondary organic aerosols with airway and systemic inflammation in an elderly panel cohort. Epidemiology 21(6), 892-902 (2010).

64. Chuang KJ, Chan CC, Su TC, Lee CT, Tang CS. The effect of urban air pollution on inflammation, oxidative stress, coagulation, and autonomic dysfunction in young adults. Am. J. Respir. Crit. Care Med. 176(4), 370-376 (2007)

65. Shigenaga MK, Ames BN. Assays for 8-hydroxy-2'-deoxyguanosine: a biomarker of in vivo oxidative DNA damage. Free Radic. Biol. Med. 10(3-4), 211-216 (1991).

66. Ren C, Fang S, Wright RO, Suh H, Schwartz J. Urinary 8-hydroxy-2'-deoxyguanosine as a biomarker of oxidative DNA damage induced by ambient pollution in the normative aging study. Occup. Environ. Med. 68(8), 562-569 (2011).

67. Bagryantseva Y, Novotna B, Rossner P Jr et al. Oxidative damage to biological macromolecules in Prague bus drivers and garagemen: impact of air pollution and genetic polymorphisms. Toxicol. Lett. 199(1), 60-68 (2010).

68. Rossner P Jr, Rossnerova A, Sram RJ Oxidative stress and chromosomal aberrations in an environmentally exposed population. Mutat. Res. 707(1-2), 34-41 (2011).

69. Bae S, Pan XC, Kim SY et al. Exposures to particulate matter and polycyclic aromatic hydrocarbons and oxidative stress in schoolchildren. Environ. Health Perspect. 118(4), 579-583 (2010).

70. Sorensen M, Daneshvar B, Hansen M et al. Personal PM2.5 exposure and markers of oxidative stress in blood. Environ. Health Perspect. 111(2), 161-166 (2003).
71. Liu L, Ruddy T, Dalipaj M et al. Effects of indoor, outdoor, and personal exposure to particulate air pollution on cardiovascular physiology and systemic mediators in seniors. J. Occup. Environ. Med. 51(9), 1088-1098 (2009).

72. Mordukhovich I, Wilker E, Suh H et al. Black carbon exposure, oxidative stress genes, and blood pressure in a repeated-measures study. Environ. Health Perspect. 117(11), 1767-1772 (2009).

73. Delfino RJ, Staimer N, Tjoa T et al. Circulating biomarkers of inflammation, antioxidant activity, and platelet activation are associated with primary combustion aerosols in subjects with coronary artery disease. Environ. Health Perspect. 116(7), 898-906 (2008).

74. Behndig AF, Mudway IS, Brown JL et al. Airway antioxidant and inflammatory responses to diesel exhaust exposure in healthy humans. Eur. Respir. J. 27(2), 359-365 (2006).

75. Mudway IS, Stenfors N, Duggan ST et al. An in vitro and in vivo investigation of the effects of diesel exhaust on human airway lining fluid antioxidants. Arch. Biochem. Biophys. 423(1), 200-212 (2004).

76. Mills NL, Robinson SD, Fokkens PH et al. Exposure to concentrated ambient particles does not affect vascular function in patients with coronary heart disease. Environ. Health Perspect. 116(6), 709-715 (2008).

77. Peretz A, Peck EC, Bammler TK et al. Diesel exhaust inhalation and assessment of peripheral blood mononuclear cell gene transcription effects: an exploratory study of healthy human volunteers. Inhal. Toxicol. 19(14), 1107-1119 (2007).

78. Brauner EV, Forchhammer L, Moller P et al. Indoor particles affect vascular function in the aged: an air filtration-based intervention study. Am. J. Respir. Crit. Care Med. 177(4), 419-425 (2008)

79. Allen RW, Carlsten C, Karlen B et al. An air filter intervention study of endothelial function among healthy adults in a woodsmoke-impacted community. Am. J. Respir. Crit. Care Med. 183(9), 1222-1230 (2011).

80. Allen J, Trenga CA, Peretz A, Sullivan JH, Carlsten CC, Kaufman JD. Effect of diesel exhaust inhalation on antioxidant and oxidative stress responses in adults with metabolic syndrome. Inhal. Toxicol. 21(13), 1061-1067 (2009).

81. Gilliland FD, Li YF, Saxon A, Diaz-Sanchez D. Effect of glutathione- $S$-transferase M1 and P1 genotypes on xenobiotic enhancement of allergic responses: randomised, placebocontrolled crossover study. Lancet 363(9403), 119-125 (2004).
82. Kipen HM, Gandhi S, Rich DQ et al. Acute decreases in proteasome pathway activity after inhalation of fresh diesel exhaust or secondary organic aerosol. Environ. Health Perspect. 119(5), 658-663 (2011).

83. Moller P, Loft S. Oxidative damage to DNA and lipids as biomarkers of exposure to air pollution. Environ. Health Perspect. 118(8), 1126-1136 (2010).

- Comprehensive and systematic analysis of the clinical evidence for oxidative stress following exposure to PM.

84. Okayama Y, Kuwahara M, Suzuki AK, Tsubone $\mathrm{H}$. Role of reactive oxygen species on diesel exhaust particle-induced cytotoxicity in rat cardiac myocytes. $J$. Toxicol. Environ. Health Part A 69(18), 1699-1710 (2006).

85. Ikeda M, Suzuki M, Watarai K, Sagai M, Tomita T. Impairment of endotheliumdependent relaxation by diesel exhaust particles in rat thoracic aorta. Jpn J. Pharmacol. 68(2), 183-189 (1995).

86. Stoeger T, Takenaka S, Frankenberger B et al. Deducing in vivo toxicity of combustionderived nanoparticles from a cell-free oxidative potency assay and metabolic activation of organic compounds. Environ. Health Perspect. 117(1), 54-60 (2009).

87. Aam BB, Fonnum F. ROS scavenging effects of organic extract of diesel exhaust particles on human neutrophil granulocytes and rat alveolar macrophages. Toxicology 230(2-3), 207-218 (2007).

88. Miller MR, Borthwick SJ, Shaw CA et al. Direct impairment of vascular function by diesel exhaust particulate through reduced bioavailability of endothelium-derived nitric oxide induced by superoxide free radicals. Environ. Health Perspect. 117(4), 611-616 (2009).

89. Salonen RO, Halinen AI, Pennanen AS et al. Chemical and in vitro toxicologic characterization of wintertime and springtime urban-air particles with an aerodynamic diameter below 10 microm in Helsinki. Scand. J. Work Environ. Health 30 (Suppl. 2), 80-90 (2004).

90. Kumagai Y, Taira J, Sagai M. Apparent inhibition of superoxide dismutase activity in vitro by diesel exhaust particles. Free Radic. Biol. Med. 18(2), 365-371 (1995).

91. Sagai M, Saito H, Ichinose T, Kodama M, Mori Y. Biological effects of diesel exhaust particles. I. In vitro production of superoxide and in vivo toxicity in mouse. Free Radic. Biol. Med. 14(1), 37-47 (1993).

92. Healey K, Smith EC, Wild CP, Routledge $\mathrm{MN}$. The mutagenicity of urban particulate matter in an enzyme free system is associated 
with the generation of reactive oxygen species. Mutat. Res. 602(1-2), 1-6 (2006).

93. Muto E, Hayashi T, Yamada K, Esaki T, Sagai M, Iguchi A. Endothelial-constitutive nitric oxide synthase exists in airways and diesel exhaust particles inhibit the effect of nitric oxide. Life Sci. 59(18), 1563-1570 (1996).

94. Alaghmand M, Blough NV. Sourcedependent variation in hydroxyl radical production by airborne particulate matter. Environ. Sci. Technol. 41(7), 2364-2370 (2007).

95. Prahalad AK, Inmon J, Dailey LA, Madden MC, Ghio AJ, Gallagher JE. Air pollution particles mediated oxidative DNA base damage in a cell free system and in human airway epithelial cells in relation to particulate metal content and bioreactivity. Chem. Res. Toxicol. 14(7), 879-887 (2001).

96. Shi T, Duffin R, Borm PJ, Li H, Weishaupt C, Schins RP. Hydroxyl-radical-dependent DNA damage by ambient particulate matter from contrasting sampling locations. Environ. Res. 101(1), 18-24 (2006).

97. Shaw CA, Robertson S, Miller MR et al. Diesel exhaust particulate - exposed macrophages cause marked endothelial cell activation. Am. J. Respir. Cell. Mol. Biol. 44(6), 840-851 (2011).

98. Hirano S, Furuyama A, Koike E, Kobayashi T. Oxidative-stress potency of organic extracts of diesel exhaust and urban fine particles in rat heart microvessel endothelial cells. Toxicology 187(2-3), 161-170 (2003).

99. Sumanasekera WK, Ivanova MM, Johnston BJ et al. Rapid effects of diesel exhaust particulate extracts on intracellular signaling in human endothelial cells. Toxicol. Lett. 174(1-3), 61-73 (2007).

100. Sun Q, Yue P, Kirk RI et al. Ambient air particulate matter exposure and tissue factor expression in atherosclerosis. Inhal. Toxicol. 20 (2), 127-137 (2008).

101. Mills NL, Miller MR. Particles and the vascular endothelium. In: Cardiovascular Effects of Inhaled Ultrafine and Nanosized Particles. Cassee FR, Mills NL, Newby DE (Eds). J Wiley and Sons Inc., NJ, USA 379-402 (2011).

102. Jimenez LA, Drost EM, Gilmour PS et al. PM(10)-exposed macrophages stimulate a proinflammatory response in lung epithelial cells via TNF- $\alpha$. Am. J. Physiol. 282(2), L237-L248 (2002)

103. Chio CP, Chen SC, Chiang KC, Chou WC, Liao CM. Oxidative stress risk analysis for exposure to diesel exhaust particle-induced reactive oxygen species. Sci. Total Environ. 387(1-3), 113-127 (2007).
104. Ohyama M, Otake T, Adachi S, Kobayashi T, Morinaga K. A comparison of the production of reactive oxygen species by suspended particulate matter and diesel exhaust particles with macrophages. Inhal. Toxicol. 19(Suppl. 1), 157-160 (2007).

105. Bai Y, Suzuki AK, Sagai M. The cytotoxic effects of diesel exhaust particles on human pulmonary artery endothelial cells in vitro: role of active oxygen species. Free Radic. Biol. Med. 30 (5), 555-562 (2001).

106. Li R, Ning Z, Cui J et al. Ultrafine particles from diesel engines induce vascular oxidative stress via JNK activation. Free Radic. Biol. Med. 46(6), 775-782 (2009).

107. Li R, Ning Z, Majumdar R et al. Ultrafine particles from diesel vehicle emissions at different driving cycles induce differential vascular pro-inflammatory responses: Implication of chemical components and NF-KB signalling. Part. Fibre Toxicol. 7, 6 (2010).

108. Montiel-Davalos A, Ibarra-Sanchez Mde J, Ventura-Gallegos JL, Alfaro-Moreno E, Lopez-Marure R. Oxidative stress and apoptosis are induced in human endothelial cells exposed to urban particulate matter. Toxicol. In Vitro 24(1), 135-141 (2010).

109. Furuyama A, Hirano S, Koike E, Kobayashi $T$. Induction of oxidative stress and inhibition of plasminogen activator inhibitor-1 production in endothelial cells following exposure to organic extracts of diesel exhaust particles and urban fine particles. Arch. Toxicol. 80(3), 154-162 (2006).

110. Karoly ED, Li Z, Dailey LA, Hyseni X, Huang YC. Up-regulation of tissue factor in human pulmonary artery endothelial cells after ultrafine particle exposure. Environ. Health Perspect. 115(4), 535-540 (2007).

111. van Eeden SF, Tan WC, Suwa T et al. Cytokines involved in the systemic inflammatory response induced by exposure to particulate matter air pollutants (PM(10)). Am. J. Respir. Crit. Care Med. 164(5), 826-830 (2001).

112. Fujii T, Hayashi S, Hogg JC et al. Interaction of alveolar macrophages and airway epithelial cells following exposure to particulate matter produces mediators that stimulate the bone marrow. Am. J. Respir. Cell. Mol. Biol. 27(1), 34-41 (2002).

113. Kristovich R, Knight DA, Long JF, Williams MV, Dutta PK, Waldman WJ. Macrophagemediated endothelial inflammatory responses to airborne particulates: impact of particulate physicochemical properties. Chem. Res. Toxicol. 17(10), 1303-1312 (2004).

114. Bachoual R, Boczkowski J, Goven D et al. Biological effects of particles from the Paris subway system. Chem. Res. Toxicol. 20(10), 1426-1433 (2007).

115. Alfaro-Moreno E, Martinez L, Garcia-Cuellar $\mathrm{C}$ et al. Biologic effects induced in vitro by PM10 from three different zones of Mexico City. Environ. Health Perspect. 110(7), 715-720 (2002).

116. Frikke-Schmidt H, Roursgaard M, Lykkesfeldt J, Loft S, Nojgaard JK, Moller P. Effect of vitamin $\mathrm{C}$ and iron chelation on diesel exhaust particle and carbon black induced oxidative damage and cell adhesion molecule expression in human endothelial cells. Toxicol. Lett. 203(3), 181-189 (2011).

117. Aung HH, Lame MW, Gohil Ket al. Comparative gene responses to collected ambient particles in vitro: endothelial responses. Physiol. Genomics 43(15), 917-929 (2011).

118. Kafoury RM, Madden MC. Diesel exhaust particles induce the over expression of tumor necrosis factor- $\alpha$ (TNF- $\alpha$ ) gene in alveolar macrophages and failed to induce apoptosis through activation of nuclear factor- $\kappa \mathrm{B}$ (NF-кB). Int. J. Environ. Res. Public Health 2(1), 107-113 (2005).

119. Lindbom J, Gustafsson M, Blomqvist G et al. Exposure to wear particles generated from studded tires and pavement induces inflammatory cytokine release from human macrophages. Chem. Res. Toxicol. 19(4), 521-530 (2006).

120. Imrich A, Ning Y, Lawrence J et al. Alveolar macrophage cytokine response to air pollution particles: oxidant mechanisms. Toxicol. Appl. Pharmacol. 218(3), 256-264 (2007).

121. Mo Y, Wan R, Chien S, Tollerud DJ, Zhang Q. Activation of endothelial cells after exposure to ambient ultrafine particles: the role of $\mathrm{NADPH}$ oxidase. Toxicol. Appl. Pharmacol. 236(2), 183-193 (2009).

122. Cheng YW, Kang JJ. Inhibition of agonistinduced vasocontraction and impairment of endothelium-dependent vasorelaxation by extract of motorcycle exhaust particles in vitro. J. Toxicol. Environ. Health A 57(2), 75-87 (1999).

123. Courtois A, Andujar P, Ladeiro Y et al. Impairment of NO-dependent relaxation in intralobar pulmonary arteries: comparison of urban particulate matter and manufactured nanoparticles. Environ. Health Perspect. 116(10), 1294-1299 (2008).

- Excellent use of functioning isolated arteries to provide a thorough analysis of the pathways involved in the direct vascular impairment of urban PM, in comparison with that of 'clean' particles, in vitro. In a subset of experiments the data are compared with that from pulmonary administration of particles in vivo. 
124. Knaapen AM, den Hartog GJ, Bast A, Borm PJ. Ambient particulate matter induces relaxation of rat aortic rings in vitro. Hum. Exp. Toxicol. 20(5), 259-265 (2001).

125. Tzeng HP, Yang RS, Ueng TH, Lin-Shiau SY, Liu SH. Motorcycle exhaust particulates enhance vasoconstriction in organ culture of rat aortas and involve reactive oxygen species. Toxicol. Sci. 75(1), 66-73 (2003).

126. Knuckles TL, Lund AK, Lucas SN, Campen MJ. Diesel exhaust exposure enhances venoconstriction via uncoupling of eNOS. Toxicol Appl. Pharmacol, 230(3), 346-351 (2008).

127. Proctor SD, Dreher KL, Kelly SE, Russell JC. Hypersensitivity of prediabetic JCR:LA-cp rats to fine airborne combustion particle-induced direct and noradrenergicmediated vascular contraction. Toxicol. Sci. 90(2), 385-391 (2006).

128. Hartz AM, Bauer B, Block ML, Hong JS, Miller DS. Diesel exhaust particles induce oxidative stress, proinflammatory signaling, and P-glycoprotein up-regulation at the blood-brain barrier. FASEB J. 22(8), 2723-2733 (2008).

129. Campen MJ, Babu NS, Helms GA et al. Nonparticulate components of diesel exhaust promote constriction in coronary arteries from $\mathrm{ApoE}^{-1-}$ mice. Toxicol. Sci. 88(1), 95-102 (2005).

130. Sun Y, Taguchi K, Sumi D, Yamano S, Kumagai Y. Inhibition of endothelial nitric oxide synthase activity and suppression of endothelium-dependent vasorelaxation by 1,2-naphthoquinone, a component of diesel exhaust particles. Arch. Toxicol. 80(5), 280-285 (2006).

131. Stampfl A, Maier M, Radykewicz R, Reitmeir P, Gottlicher M, Niessner R. Langendorff heart: a model system to study cardiovascular effects of engineered nanoparticles. ACS Nano 5(7), 5345-5353 (2011).

132. Radomski A, Jurasz P, Alonso-Escolano D et al. Nanoparticle-induced platelet aggregation and vascular thrombosis. Br. J. Pharmacol. 146(6), 882-893 (2005).

133. Nemmar A, Zia S, Subramaniyan D, Fahim MA, Ali BH. Exacerbation of thrombotic events by diesel exhaust particle in mouse model of hypertension. Toxicology 285(1-2), 39-45 (2011).

134. Kilinc E, Van Oerle R, Borissoff JI et al. Factor XII activation is essential to sustain the procoagulant effects of particulate matter. J. Thromb. Haemost. 9(7), 13591367 (2011).

135. Nemmar A, Al-Salam S, Zia S et al. Contrasting actions of diesel exhaust particles on the pulmonary and cardiovascular systems and the effects of thymoquinone. Br. J. Pharmacol. 164(7), 1871-1882 (2011).

136. Metassan S, Charlton AJ, Routledge MN, Scott DJ, Ariens RA. Alteration of fibrin clot properties by ultrafine particulate matter. Thromb. Haemost. 103(1), 103-113 (2010).

137. Nurkiewicz TR, Porter DW, Barger M et al. Systemic microvascular dysfunction and inflammation after pulmonary particulate matter exposure. Environ. Health Perspect. 114(3), 412-419 (2006).

138. Nemmar A, Dhanasekaran S, Yasin J et al. Evaluation of the direct systemic and cardiopulmonary effects of diesel particles in spontaneously hypertensive rats. Toxicology 262(1), 50-56 (2009).

139. Chang CC, Hwang JS, Chan CC, Cheng TJ. Interaction effects of ultrafine carbon black with iron and nickel on heart rate variability in spontaneously hypertensive rats. Environ. Health Perspect. 115(7), 1012-1017 (2007).

140. Zhao J, Cao Q, Qian X et al. Acute effects of fine particle on cardiovascular system of rats. Wei Sheng Yan Jiu 36(4), 417-420 (2007).

141. Upadhyay S, Ganguly K, Stoeger T et al. Cardiovascular and inflammatory effects of intratracheally instilled ambient dust from Augsburg, Germany, in spontaneously hypertensive rats (SHRs). Part. Fibre Toxicol. 7, 27 (2010).

142. Bartoli CR, Wellenius GA, Diaz EA et al. Mechanisms of inhaled fine particulate air pollution-induced arterial blood pressure changes. Environ. Health Perspect. 117(3), 361-366 (2009)

143. Ghio AJ, Huang YC. Exposure to concentrated ambient particles (CAPs): a review. Inhal. Toxicol. 16(1), 53-59 (2004).

144. McQueen DS, Donaldson K, Bond SM et al. Bilateral vagotomy or atropine pre-treatment reduces experimental diesel-soot induced lung inflammation. Toxicol. Appl. Pharmacol. 219(1), 62-71 (2007).

145. Elder A, Couderc JP, Gelein R et al. Effects of on-road highway aerosol exposures on autonomic responses in aged, spontaneously hypertensive rats. Inhal. Toxicol. 19(1), 1-12 (2007).

146. Rhoden CR, Wellenius GA, Ghelfi E, Lawrence J, Gonzalez-Flecha B. PM-induced cardiac oxidative stress and dysfunction are mediated by autonomic stimulation. Biochim. Biophys. Acta 1725(3), 305-313 (2005).

147. Wellenius GA, Saldiva PH, Batalha JR et al. Electrocardiographic changes during exposure to residual oil fly ash (ROFA) particles in a rat model of myocardial infarction. Toxicol. Sci. 66(2), 327-335 (2002).
148. Xu X, Kherada N, Hong X et al. Diesel exhaust exposure induces angiogenesis. Toxicol. Lett. 191(1), 57-68 (2009).

149. O’Toole TE, Hellmann J, Wheat L et al. Episodic exposure to fine particulate air pollution decreases circulating levels of endothelial progenitor cells. Circ. Res. 107(2), 200-203 (2010).

150. Xu X, Yavar Z, Verdin M et al. Effect of early particulate air pollution exposure on obesity in mice: role of p47phox. Arterioscler. Thromb. Vasc. Biol. 30(12), 2518-2527 (2010).

151. Sun Q, Yue P, Deiuliis JA et al. Ambient air pollution exaggerates adipose inflammation and insulin resistance in a mouse model of diet-induced obesity. Circulation 119(4), 538-546 (2009).

152. Maresh JG, Campen MJ, Reed MD, Darrow AL, Shohet RV. Hypercholesterolemia potentiates aortic endothelial response to inhaled diesel exhaust. Inhal. Toxicol. 23(1), 1-10 (2011).

153. Tamagawa E, Bai N, Morimoto K et al. Particulate matter exposure induces persistent lung inflammation and endothelial dysfunction. Am. J. Physiol. 295(1), L79-L85 (2008).

154. Ying Z, Yue P, Xu X et al. Air pollution and cardiac remodeling: a role for RhoA/ Rho-kinase. Am. J. Physiol. 296(5), H1540-H1550 (2009).

155. Cozzi E, Hazarika S, Stallings HW 3rd et al. Ultrafine particulate matter exposure augments ischemia-reperfusion injury in mice. Am. J. Physiol. 291(2), H894-H903 (2006).

- Use of a rat model of myocardial infarction (coronary ligation) demonstrating that urban PM increases the size of the infarcted region of the heart, an effect that is associated with raised levels of oxidative stress and infiltration of inflammatory cells within the infarcted region.

156. Vesterdal LK, Folkmann JK, Jacobsen NR et al. Pulmonary exposure to carbon black nanoparticles and vascular effects. Part. Fibre Toxicol. 7, 33 (2010).

157. Ying Z, Kampfrath T, Thurston G et al. Ambient particulates alter vascular function through induction of reactive oxygen and nitrogen species. Toxicol. Sci. 111(1), 80-88 (2009).

158. Moller P, Mikkelsen L, Vesterdal LK et al. Hazard identification of particulate matter on vasomotor dysfunction and progression of atherosclerosis. Crit. Rev. Toxicol. 41(4), 339-368 (2011).

159. Cherng TW, Paffett ML, Jackson-Weaver O, Campen MJ, Walker BR, Kanagy NL. Mechanisms of diesel-induced endothelial 
nitric oxide synthase dysfunction in coronary arterioles. Environ. Health Perspect. 119(1), 98-103 (2011).

160. Nemmar A, Al-Salam S, Dhanasekaran S, Sudhadevi M, Ali BH. Pulmonary exposure to diesel exhaust particles promotes cerebral microvessel thrombosis: protective effect of a cysteine prodrug 1-2-oxothiazolidine-4carboxylic acid. Toxicology 263(2-3), 84-92 (2009).

161. Nurkiewicz TR, Porter DW, Barger M, Castranova V, Boegehold MA. Particulate matter exposure impairs systemic microvascular endothelium-dependent dilation. Environ. Health Perspect. 112(13), 1299-1306 (2004).

162. Dvonch JT, Brook RD, Keeler GJ et al. Effects of concentrated fine ambient particles on rat plasma levels of asymmetric dimethylarginine. Inhal. Toxicol. 16(6-7), 473-480 (2004).

163. Wan G, Rajagopalan S, Sun Q, Zhang K. Real-world exposure of airborne particulate matter triggers oxidative stress in an animal model. Int. J. Physiol. Pathophysiol. Pharmacol. 2(1), 64-68 (2010)

164. Ghelfi E, Wellenius GA, Lawrence J, Millet E, Gonzalez-Flecha B. Cardiac oxidative stress and dysfunction by fine concentrated ambient particles (CAPs) are mediated by angiotensin-II. Inhal. Toxicol. 22(11), 963-972 (2010).

165. Gurgueira SA, Lawrence J, Coull B, Murthy GG, Gonzalez-Flecha B. Rapid increases in the steady-state concentration of reactive oxygen species in the lungs and heart after particulate air pollution inhalation. Environ. Health Perspect. 110 (8), 749-755 (2002).

166. Sun Q, Wang A, Jin X et al. Long-term air pollution exposure and acceleration of atherosclerosis and vascular inflammation in an animal model. JAMA, 294(23), 3003-3010 (2005).

- One of the initial studies demonstrating the proatherosclerotic effects of air pollution in $\mathrm{ApoE}^{-/-}$mice. Extensive characterization of the mechanisms of the vascular effects (oxidative stress, inflammation and endothelial dysfunction) through an impressive array of techniques.

167. Lund AK, Knuckles TL, Obot Akata C et al. Gasoline exhaust emissions induce vascular remodeling pathways involved in atherosclerosis. Toxicol. Sci. 95(2), 485-494 (2007).

168. Lund AK, Lucero J, Harman M et al. The oxidized low-density lipoprotein receptor mediates vascular effects of inhaled vehicle emissions. Am. J. Respir. Crit. Care Med. 184(1), 82-91 (2011).
- Interesting study with a novel proposal that an increase in lectin-like oxidized LDL receptors (LOX-1) mediates the atherogenic effect of inhalation of mixed engine exhaust in $\mathrm{ApoE}^{-/-}$knockout mice. In addition, diesel exhaust inhalation in man increased soluble LOX-1 in plasma. See also [173]; proposing a role for oxidized LDL in the atherosclerotic effects of PM via loss of the antioxidant effect of HDL.

169. Damaceno-Rodrigues NR, Veras MM, Negri EM et al. Effect of pre- and postnatal exposure to urban air pollution on myocardial lipid peroxidation levels in adult mice. Inhal. Toxicol. 21(13), 1129-1137 (2009).

170. Bai N, Kido T, Suzuki H et al. Changes in atherosclerotic plaques induced by inhalation of diesel exhaust. Atherosclerosis 216(2), 299-306 (2011).

171. Bai N, Kido T, Kavanagh TJ et al. Exposure to diesel exhaust up-regulates iNOS expression in ApoE knockout mice. Toxicol. Appl. Pharmacol. 255(2), 184-192 (2011).

172. Gong KW, Zhao W, Li N et al. Air-pollutant chemicals and oxidized lipids exhibit genomewide synergistic effects on endothelial cells. Genome Biol. 8(7), R149 (2007).

173. Araujo JA, Barajas B, Kleinman M et al. Ambient particulate pollutants in the ultrafine range promote early atherosclerosis and systemic oxidative stress. Circ. Res. 102(5), 589-596 (2008).

174. Kampfrath T, Maiseyeu A, Ying Z et al. Chronic fine particulate matter exposure induces systemic vascular dysfunction via NADPH oxidase and TLR4 pathways. Circ. Res. 108(6), 716-726 (2011).

- Recent preclinical study providing novel insights into the role of NADPH oxidase in the cardiovascular effects of air pollution, hypothesizing a role for oxidized phospholipid derivatives in mediating the signal transduction (see [177] and [157] from the same group for additional mechanistic processes).

175. Ulrich MM, Alink GM, Kumarathasan P, Vincent R, Boere AJ, Cassee FR. Health effects and time course of particulate matter on the cardiopulmonary system in rats with lung inflammation. J. Toxicol. Environ. Health A. 65(20), 1571-1595 (2002).

176. Lund AK, Lucero J, Lucas S et al. Vehicular emissions induce vascular MMP-9 expression and activity associated with endothelin-1mediated pathways. Arterioscler. Thromb. Vasc. Biol. 29(4), 511-517 (2009).

177. Sun Q, Yue P, Ying Z et al. Air pollution exposure potentiates hypertension through reactive oxygen species-mediated activation of
Rho/ROCK. Arterioscler. Thromb. Vascular. Biol. 28(10), 1760-1766 (2008).

178. Gottipolu RR, Wallenborn JG, Karoly ED et al. One-month diesel exhaust inhalation produces hypertensive gene expression pattern in healthy rats. Environ. Health Perspect. 117(1), 38-46 (2009)

179. Suwa T, Hogg JC, Quinlan KB, Ohgami A, Vincent R, van Eeden SF. Particulate air pollution induces progression of atherosclerosis. J. Am. Coll. Cardiol. 39(6), 935-942 (2002).

180. Araujo JA, Nel AE. Particulate matter and atherosclerosis: role of particle size, composition and oxidative stress. Part. Fibre Toxicol. 6, 24 (2009).

181. Sun Q, Hong X, Wold LE. Cardiovascular effects of ambient particulate air pollution exposure. Circulation 121(25), 2755-2765 (2010).

182. Yatera K, Hsieh J, Hogg JC et al. Particulate matter air pollution exposure promotes recruitment of monocytes into atherosclerotic plaques. Am. J. Physiol. 294(2), H944-H953 (2008).

183. Tranfield EM, van Eeden SF, Yatera K, Hogg JC, Walker DC. Ultrastructural changes in atherosclerotic plaques following the instillation of airborne particulate matter into the lungs of rabbits. Can. J. Cardiol. 26(7), E258-E269 (2010).

184. Kido T, Bai N, Yatera K et al. Diesel exhaust inhalation induces heat shock protein 70 expression in vivo. Inhal. Toxicol. 23(10), 593-601 (2011)

185. Ikeda M, Shitashige M, Yamasaki H, Sagai M, Tomita T. Oxidative modification of low density lipoprotein by diesel exhaust particles. Biol. Pharm. Bull. 18(6), 866-871 (1995).

186. Soares SR, Carvalho-Oliveira R, RamosSanchez E et al. Air pollution and antibodies against modified lipoproteins are associated with atherosclerosis and vascular remodeling in hyperlipemic mice. Atherosclerosis 207(2), 368-373 (2009).

187. Campen MJ, Lund AK, Knuckles TL et al. Inhaled diesel emissions alter atherosclerotic plaque composition in ApoE(-/-) mice. Toxicol. Appl. Pharmacol. 242(3), 310-317 (2010).

188. Lucking AJ, Lundback M, Barath SL et al. Particle traps prevent adverse vascular and prothrombotic effects of diesel engine exhaust inhalation in men. Circulation. 123(16), 1721-1728 (2011).

189. Quan C, Sun Q, Lippmann M, Chen LC. Comparative effects of inhaled diesel exhaust and ambient fine particles on inflammation, atherosclerosis, and vascular dysfunction. Inhal. Toxicol. 22(9), 738-753 (2010). 
190. Singh P, DeMarini DM, Dick CA et al. Sample characterization of automobile and forklift diesel exhaust particles and comparative pulmonary toxicity in mice. Environ. Health Perspect. 112(8), 820-825 (2004).

191. DeMarini DM, Brooks LR, Warren SH, Kobayashi T, Gilmour MI, Singh P. Bioassay-directed fractionation and Salmonella mutagenicity of automobile and forklift diesel exhaust particles. Environ. Health Perspect. 112(8), 814-819 (2004).

192. Niwa Y, Hiura Y, Murayama T, Yokode M, Iwai N. Nano-sized carbon black exposure exacerbates atherosclerosis in LDL-receptor knockout mice. Circ. J. 71(7), 1157-1161 (2007).

193. Upadhyay S, Stoeger T, Harder V et al. Exposure to ultrafine carbon particles at levels below detectable pulmonary inflammation affects cardiovascular performance in spontaneously hypertensive rats. Part. Fibre Toxicol. 5, 19 (2008).

194. Nurkiewicz TR, Porter DW, Hubbs AF et al. Pulmonary nanoparticle exposure disrupts systemic microvascular nitric oxide signaling. Toxicol. Sci. 110(1), 191-203 (2009).

195. Elder AC, Gelein R, Azadniv M, Frampton M, Finkelstein J, Oberdorster G. Systemic effects of inhaled ultrafine particles in two compromised, aged rat strains. Inhal. Toxicol. 16(6-7), 461-471 (2004)
196. Clancy L, Goodman P, Sinclair H, Dockery D. Effect of air-pollution control on death rates in Dublin, Ireland: an intervention study. Lancet 360, 1210-1214 (2002).

197. Pell JP, Haw S, Cobbe S et al. Smoke-free legislation and hospitalizations for acute coronary syndrome. N. Engl. J. Med. 359(5), 482-491 (2008)

198. Meyers DG, Neuberger JS, He J. Cardiovascular effect of bans on smoking in public places: a systematic review and meta-analysis. J. Am. Coll. Cardiol. 54(14), 1249-1255 (2009).

199. Schwartz J, Park SK, O’Neill MS et al. Glutathione- $S$-transferase M1, obesity, statins, and autonomic effects of particles: gene-by-drug-by-environment interaction. Am. J. Respir. Crit. Care Med. 172(12), 1529-1533 (2005).

200. Barclay JL, Miller BG, Dick S et al. A panel study of air pollution in subjects with heart failure: negative results in treated patients. Occup. Environ. Med. 66(5), 325-334 (2009).

201. Langrish JP, Mills NL, Chan JK et al. Beneficial cardiovascular effects of reducing exposure to particulate air pollution with a simple facemask. Part. Fibre Toxicol. 6, 8 (2009).

202. Langrish JP, Li J, Wang S et al. Reducing particulate air pollution exposure in patients with coronary heart disease improved cardiovascular health. Environ. Health Perspect. 120(3), 367-372 (2012).

203. Freney EJ, Heal MR, Donovan RJ et al. A single-particle characterization of a mobile versatile aerosol concentration enrichment system for exposure studies. Part. Fibre Toxicol. 3, 8 (2006).

204. Lehnert BE. Pulmonary and thoracic macrophage subpopulations and clearance of particles from the lung. Environ. Health Perspect. 97, 17-46 (1992).

\section{Websites}

301. WHO. Air quality and health. WHO Factsheets. www.who.int/mediacentre/factsheets/ fs $313 /$ en

302. Greater London Authority. 50 years on: the struggle for air quality in London since the great smog of December 1952. www.london.gov.uk/mayor/environment/ air_quality/docs/50_years_on.pdf

303. Project on emerging nanotechnologies. consumer products: an inventory of nanotechnology-based consumer products currently on the market. www.nanotechproject.org/inventories/ consumer 